Einführung 


\title{
Funktionen und Steuerung von Wahlmöglichkeiten und Wettbewerb im Gesundheitswesen
}

\author{
Ulrich Becker
}

I. Mehr Effizienz durch Wettbewerb? - Ausgangspunkt und Ziel des Projekts

II. Die Komplexität der Rechtsbeziehungen - zu den Beteiligten und deren

Rollen im Leistungsdreieck

1. Vom Behandlungsvertrag zum sog. Leistungserbringungsverhältnis

1.1. Ausgangspunkt: Rechtsverhältnis zwischen Patient und Arzt

1.2. Das Versicherungsverhältnis

1.3. Das Sozialleistungs- und das Leistungserbringungsverhältnis 18

2. Erweiterungen

2.1. Die Rolle des Staates: Regulierungen

2.2. Mögliche Zwischenebene: Korporatistische Arrangements

2.3. Die Rolle der Arbeitgeber

III. Wettbewerb und Gesundheitsleistungen - theoretische Vorüberlegungen zu

Wahlmöglichkeiten und deren Steuerung

1. $\mathrm{Zu}$ den Funktionen von Wettbewerb und Sozialleistungssystemen 27

1.1. Ausgangspunkte

1.2. Funktionen von sozialen Sicherungssystemen $\quad 30$

1.3. Funktionen des Wettbewerbs $\quad 32$

2. Wahlmöglichkeiten und die Anwendung des Wettbewerbs- und Sozialrechts 34

2.1. Handlungsfreiheiten

2.2. Tatsächliche Handlungsmöglichkeiten 35

2.3. Verläßlichkeit $\quad 36$

IV. Wahlmöglichkeiten im Leistungsdreieck - zur Länderauswahl 37

1. Wahlmöglichkeiten trotz Anbietermonopols 37

$\begin{array}{ll}\text { 1.1. Bezogen auf das Versicherungsverhältnis } & 37\end{array}$

1.2. Bezogen auf das Leistungserbringungsverhältnis 38

2. Wettbewerb auf Angebotsseite $\quad 42$

2.1. Wahlmöglichkeiten auf Angebotsseite 42

2.2. Konsequenzen für die Leistungserbringung 46

V. Besonderheiten des Krankenhaussektors - zum Aufbau der Untersuchung 49

1. Krankenhäuser als institutioneller Ausgangspunkt 49

2. Zu den Rechtsverhältnissen bei der Versorgung im Krankenhaus 51

3. Zur Einbettung in die Gesamtrechtsordnung und den faktischen Hintergründen 


\section{Mehr Effizienz durch Wettbewerb? - Ausgangspunkt und Ziel des Projekts}

1. Wettbewerb dient dazu, auf einem Markt Tauschmöglichkeiten zu eröffnen und zu erhalten. Idealerweise entscheiden die Marktteilnehmer über Menge und Preis von Gütern. Sie folgen dabei ihren eigenen Präferenzen. Das setzt die Existenz von Wahlmöglichkeiten voraus. Entsprechende Möglichkeiten bestehen keineswegs immer. Für sie bedarf es einer rechtlichen Ordnung. Dabei kommt dem Staat die Aufgabe zu, die Bedingungen für einen funktionierenden Wettbewerb sicherzustellen. Das Erfordernis staatlicher Regelung folgt aus Marktunvollkommenheiten (oder dem Marktversagen) wie aus dem Bestreben der Wettbewerber, den Wettbewerb durch Erringung einer starken Position zu verringern oder auszuschalten. Instrument der Sicherung des Wettbewerbs ist das Wettbewerbsrecht. Dieses schafft die Rahmenbedingungen für den Markt. Es läßt aber das Ergebnis des Wettbewerbs für die Güterherstellung und die Güterverteilung offen.

Wettbewerb kann nicht nur als Entmachtungs-,${ }^{1}$ sondern auch als Steuerungsinstrument zur Erzielung bestimmter Ergebnisse eingesetzt werden. Nämlich dann, wenn ein gewünschtes Ergebnis vorgegeben ist. In diesem Fall wird die Ergebniserzielung zur öffentlichen Aufgabe, und der Staat muß für deren Erfüllung sorgen. Er kann dies durch besondere Regulierung des privaten Rechtsverkehrs tun und sich auf eine Gewährleistungsfunktion beschränken. Oder er kann die Aufgabenerfüllung in die eigene Hand nehmen. Selbst wenn staatliche Behörden handeln, schließt dies aber keineswegs aus, daß für die durch das Handeln Betroffenen Wahlmöglichkeiten vorgesehen werden. Solche Wahlmöglichkeiten können Spielräume für einen Wettbewerb eröffnen, der dann nicht nur in allgemeine Bahnen gelenkt, sondern zur Erfüllung öffentlicher Aufgaben gezielt eingesetzt wird. Theoretisch verspricht auch dieser Wettbewerb Effizienzgewinne: sei es durch Senkung der Preise oder Steigerung der Qualität der vom Staat bereitzustellenden Güter.

2. Der Einsatz wettbewerblicher Elemente wird gerade auch im Gesundheitswesen seit mittlerweile vielen Jahren für gewinnbringend gehalten. Das gilt nicht nur für Staaten, in denen die Sicherung einer ausreichenden Gesundheitsversorgung nur beschränkt als öffentliche Aufgabe angesehen wird, also ohnehin die Versorgung weitgehend dem Markt überlassen bleibt. Es gilt auch für Staaten, die sich selbst der Gesundheitsversorgung annehmen. Die Definition dieser Aufgabe ist eine Sache. Sie erschließt sich erst aus der konkreten Gestaltung des jeweiligen Gesundheitswesens. Wer die Aufgabe erledigt, ist eine andere. Beides hängt zwar zusammen, läßt aber Raum für Abstufungen

1 Franz Böhm, Demokratie und ökonomische Macht, Vortrag auf der internationalen Kartellkonferenz (1960), Bd. 1, S. 22: „, Der Wettbewerb ist das großartigste und genialste Entmachtungsinstrument der Geschichte. Man braucht es nur zu beschwören, alle weitere Arbeit leistet es von allein.“ 
und unterschiedlichste Systemstrukturen. Wahlmöglichkeiten können in verschiedener Form und verschiedenem Umfang eingebaut werden.

Wahlmöglichkeiten können in verschiedener Form und verschiedenem Umfang in einem Gesundheitssystem vorgesehen werden. Wo solche Möglichkeiten existieren, ist zugleich Raum für einen Wettbewerb. Ob der Staat auf einen Wettbewerb als Steuerungsinstrument setzt, hängt deshalb nicht allein von der grundsätzlichen Aufgabenstellung und der organisatorischen Ausgestaltung des Gesundheitswesens ab. Allerdings bleibt die Frage, wie ein Wettbewerb in einem Sektor funktionieren kann, der durch nichtmarktliche Bedingungen charakterisiert ist. ${ }^{2}$

Dabei geht es nicht nur um ökonomische, sondern auch um rechtliche Aspekte. Denn die Gesundheitssysteme sind in normative Vorgaben eingebettet, die über die Rechtsstellung der beteiligten Personen entscheiden. Zudem bedarf wettbewerbliches Handeln der rechtlichen Steuerung. Reichen aber im Gesundheitswesen die allgemeinen wettbewerbsrechtlichen Instrumente, zu denen neben dem Lauterkeits- und Kartellrecht auch das Vergaberecht gezählt werden soll, weil es den Zugang von Konkurrenten zu Beschaffungsmärkten regelt, aus? Gelten diese überhaupt, oder handelt es sich um einen Wettbewerb ohne Wettbewerbsrecht, der einer eigenständigen sozialrechtlichen Regelung bedarf?

Auf diese rechtlichen Fragen wird sich die vorliegende Studie konzentrieren. Darin und in dem Verzicht auf eine sozialwissenschaftliche Ergänzung liegt natürlich zugleich eine Beschränkung. Wirksamkeitsaspekte finden nur in Ansätzen Berücksichtigung. Über konkrete Ergebnisse einzelner Instrumente kann wenig gesagt werden. Jedoch erschien uns die Herausarbeitung der spezifisch juristischen Aspekte ausreichend wichtig, um diese Beschränkungen zu rechtfertigen. Eine kompensatorische Funktion kommt immerhin den ökonomischn Kommentaren zu den einzelnen Länderberichten zu.

3. Die Studie hat zum Ziel, erstens eine Bestandaufnahme zu liefern hinsichtlich der Frage, ob und wie Wahlmöglichkeiten in verschiedenen Rechtsordnungen bei der Versorgung mit Gesundheitsleistungen vorgesehen sind. Hintergrund der Annahme, daß Wahlmöglichkeiten und in deren Folge Wettbewerbsbeziehungen zu finden sein werden, ist die Komplexität der Rechtsbeziehungen, durch die Gesundheitssysteme in aller Regel geprägt sind (unten II.). Diese führt dazu, daß eine Steuerung durch hoheitliche Vorgaben erschwert wird.

Zweitens geht es darum, was genau von einem Einbau wettbewerblicher Elemente erwartet, warum er möglicherweise für zielführend gehalten und wie er reguliert - oder warum umgekehrterweise auf ihn ganz oder teilweise verzichtet wird. Alles andere als selbstverständlich ist die Erwartung positiver Effekte insbesondere dann, wenn die Gesundheitsversorgung als öffentliche Aufgabe angesehen wird. Jedoch wäre es zu kurz

2 Vgl. dazu auch die Beiträge in Aufderheide/Dabrowski (Hrsg.), Markt und Wettbewerb in der Sozialwirtschaft, Wirtschaftsethische und moralökonomische Perspektiven für den Pflegesektor, 2007, die allerdings für die Krankenversicherung keine Ergebnisse präsentieren. 
gegriffen, Wettbewerb und soziale Sicherung trotz unterschiedlicher Funktionen für miteinander unvereinbar zu halten (unten III.).

Drittens will die Studie die Bedeutung der festgestellten Wahlmöglichkeiten analysieren. Dabei geht es weniger um deren tatsächliche Wirkungen, wenn auch die dem Wettbewerb in sozialen Versorgungssystemen zugedachten Funktionen, vornehmlich die wirtschaftliche Gewährleistung allgemeiner Gesundheitsversorgung, also die Erzielung der vorausgesetzten Qualität zu möglichst niedrigen Kosten, einen brauchbaren Bewertungsmaßstab abgeben. Im Vordergrund stehen die Einpassung und Verbindung der Wahlmöglichkeiten mit bestimmten Strukturelementen der jeweiligen Rechtsordnung und des jeweiligen Gesundheitssystems. Welche Grenzen setzen verfassungsrechtliche Vorgaben? Erweisen sich allgemeine wettbewerbsrechtliche Instrumente zur Steuerung des Wettbewerbs als passend und ausreichend? Wie können gemischt regulativwettbewerblicher Konzepte am besten verfolgt werden? Dabei ist auch von Interesse, wie sich Wahlmöglichkeiten zwischen den Versicherern zu Wahlmöglichkeiten zwischen den Erbringern von Gesundheitsleistungen zueinander verhalten. Denn gerade die Verbindungslinien zwischen Versicherung und Leistungserbringung sind zumindest im deutschen Gesundheitswesen von zunehmender Bedeutung. Aus diesem Grund werden nur Länder in die Untersuchung einbezogen, die von der Architektur des jeweiligen Gesundheitssystems her die Möglichkeit zu Wettbewerbsbeziehungen sowohl zwischen den Versicherungsträgern als auch zwischen den Leistungserbringern gestatten (unten IV.).

Schließlich ist einleitend hervorzuheben, daß sich die Studie auf die Gesundheitsversorgung in Krankenhäusern konzentriert (unten V.). Ausschlaggebend dafür ist einerseits das Erfordernis, auch in vergleichender Betrachtung einen klar abgrenzbaren Bereich des Gesundheitswesens in den Blick zu nehmen. Andererseits ist die Krankenhausversorgung für die hier interessierenden Fragen von besonderem Interesse. Sie ist kostenintensiv. Die Behandlung in Krankenhäusern verursachte in Deutschland wie im obligatorischen System der Schweiz zu Beginn des neuen Jahrtausends gut ein Drittel der Leistungsausgaben, in den Niederlanden nur etwas weniger. ${ }^{3}$ Die Krankenhausversorgung ist zugleich durch hohe Komplexität gekennzeichnet. Überlegungen zur Sicherung und Verteilung der Infrastruktur spielen bei ihr schon wegen des hohen Behandlungsaufwands eine besondere Rolle. Zudem sind Träger der Krankenhäuser vielgestaltig. Diese Vielgestaltigkeit ist Ausdruck verschiedener Zwecke: Krankenhäuser dienen etwa nicht nur der Deckung lokaler Versorgungsbedarfe, sondern auch zur Deckung des Bedarfs an medizinischer Forschung. Sie können öffentliche Einrichtungen sein, aber ebenso Einrichtungen, in denen gewinnorientiert gewirtschaftet werden soll. Die Krankenhausversorgung bietet dementsprechende wegen ihrer zentralen Bedeutung für die Gesundheitsversorgung der Bevölkerung, wegen der mit ihr verbundenen hohen Kosten wie wegen des Zusammenspiels verschiedener Einrichtungen eines der wichtigsten Un-

3 Vgl. zur Entwicklung und weiteren Angaben die Länderberichte. 
tersuchungsfelder, wenn es um die Frage geht, ob Wettbewerb als Instrument zur Erreichung von Effizienzverbesserungen im Gesundheitswesen eingesetzt werden soll.

\section{Die Komplexität der Rechtsbeziehungen- zu den Beteiligten und deren Rollen im Leistungsdreieck}

\section{Vom Behandlungsvertrag zum sog. Leistungserbringungsverhältnis}

\subsection{Ausgangspunkt: Rechtsverhältnis zwischen Patient und Arzt}

Im Mittelpunkt medizinischer Behandlungen steht naturgemäß das Rechtsverhältnis zwischen Arzt und Patienten. Man kann es als Behandlungsverhältnis bezeichnen. Diesem liegt - jedenfalls soweit möglicherweise an der Behandlung beteiligte Dritte aus der Betrachtung ausgeschlossen bleiben - ein privatrechtlicher Vertrag zugrunde, mit dem die Beteiligten einen gegenseitigen Austausch vereinbaren: Der Arzt schuldet eine Dienstleistung, nämlich die Behandlung, ohne in der Regel zugleich einen Erfolg zu versprechen; ${ }^{4}$ nur unter bestimmten Umständen und ausnahmsweise geht seine Verpflichtung darüber hinaus. ${ }^{5}$ Der Patient schuldet die Bezahlung des Arztes. ${ }^{6}$

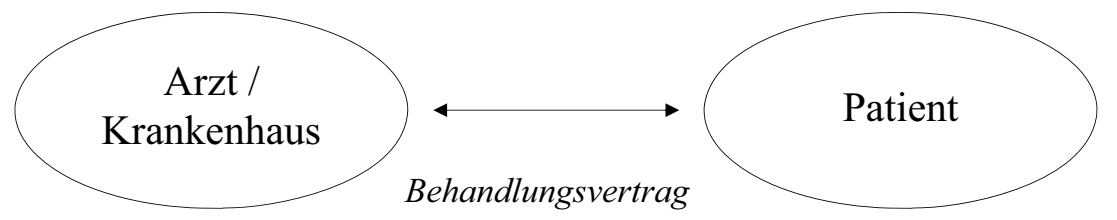

Findet die Behandlung in einem Krankenhaus statt, dann ist es möglich, daß Verträge über einzelne Leistungen gesondert geschlossen werden, also etwa über die Behandlung

4 Weshalb es sich nach deutschem Recht um einen Dienstvertrag handelt, der ausnahmsweise auch werkvertragliche Elemente enthalten kann, vgl. dazu nur Quaas/Zuck, Medizinrecht, 2. Aufl. 2008, München,, § 13 Rdnr. 2 f. m.w.N. Auch nach US-amerikanischem Recht entsteht ein Behandlungsverhältnis (treatment relationship) zwischen Patient und behandelndem Arzt durch privatrechtlichen Vertrag, mit dem der Arzt grundsätzlich die Behandlung an sich, aber nicht den Behandlungserfolg schuldet, vgl. dazu Furrow, Health Law, 2000, S. 260 ff.; Miller, Problems in Health Care Law, 2006, S. 279 ff; Showalter, The Law of Healthcare Administration, 2008, S. 25 ff.

5 Vgl. zu Fällen, in denen ein Garantieversprechen des Arztes (specific promise and warranty of cure) hinsichtlich des Behandlungserfolgs angenommen wurde, Guilmet v. Campbell, 385 Mich. 57, 188 N.W.2d 601 (1971); Sullivan v. O'Connor, 363 Mass. 579, 296 N.E.2d 183 (1973). Als Reaktion auf diese Rechtsprechung erließen einige Einzelstaaten Gesetze, wonach ein solches Garantieversprechen nur dann Gültigkeit beanspruchen kann, wenn es schriftlich abgegeben und vom behandelnden Arzt unterzeichnet wurde, vgl etwa Mich. Comp. Laws Ann. § 566.132 (Supp. 1985).

6 Vgl. zu besonderen Formen des „Arztvertrages“ Uhlenbruck, in: Laufs/Uhlenbruck, Handbuch des Arztrechts, § 39 Rdnr. 16 ff. 
einerseits und die Unterbringung andererseits. In der Praxis dürfte es aber die Regel sein, daß ein gemischter Vertrag mit dem Träger des Krankenhauses geschlossen wird, in dem sich dieser zur Erbringung ärztlicher Leistungen und zur Unterbringung sowie eventueller anderer Leistungen verpflichtet. ${ }^{7}$

Abschluß und Inhalt des Vertrags stehen, dem Grundsatz der Privatautonomie entsprechend, im Belieben der Parteien. Diese können dementsprechend sowohl den Vertragspartner als auch den Inhalt der Behandlung wählen. Allerdings wird diese Wahlfreiheit in der Praxis kaum in vollem Umfang gegeben sein. Ein Patient, der einer Behandlung bedarf, wird kaum auf den Vertragsabschluß verzichten wollen. Weil medizinische Behandlungen im wahrsten Sinne des Wortes lebenswichtige Bedeutung haben können, wird auch der Arzt in Rechtsordnungen, die um den Lebensschutz bemüht sind, keine völlige Freiheit zum Nichtabschluß von Behandlungsverträgen haben und zumindest in Notfällen zur Behandlung verpflichtet sein. ${ }^{8}$ Auch die Wahl des Vertragspartners ist aus faktischen Gründen oftmals beschränkt. Das gilt jedenfalls dann, wenn eine Behandlung erforderlich ist, deren Durchführung spezielles Fachwissen oder eine stationäre Unterbringung voraussetzt. Und schließlich führen die Besonderheiten des Behandlungsvertrags auch zu inhaltlichen Vorgaben: Wegen der erforderlichen besonderen Fachkunde des Arztes besteht eine Informationsasymmetrie; weil der Patient auf die Behandlung mehr oder weniger dringend angewiesen ist, wird er bereit sein zu unverhältnismäßigen Gegenleistungen. Ein Verhandlungsgleichgewicht fehlt also, für Patienten besteht besonderer Schutzbedarf. Deshalb existieren regelmäßig rechtliche Vorgaben. Zum einen über das Berufsrecht der Ärzte, zum anderen oftmals über Gebührenordnungen und anderen Verbraucherschutzregelungen. Damit wird den Spezifika der ärztlichen Behandlung Rechnung getragen. Betrachtet man die dazu eingesetzten Mittel, so finden sich häufig Kombinationen aus einer Selbstregulierung (Standesrecht der Ärzteschaft) und staatlicher Regulierung, wobei vor allem auch das privatrechtliche Haftungsrecht als Transmissionsriemen für die Einfügung der entsprechenden rechtlichen Vorgaben in das Behandlungsverhältnis dient, ${ }^{9}$ weil es Sekundäransprüche bereitstellt, die an einen Sorgfaltsverstoß anknüpfen und die Sorgfaltsmaßstäbe wiederum durch

7 Wobei in Deutschland die gesetzlichen Regelungen der Vergütung eine Rolle spielen; vgl. zum sog. einheitlichen oder totalen Krankenhausaufnahmevertrag und zum v.a. im Belegarztwesen verbreiteten gespaltenen Krankanhausaufnahmevertrag nur Quaas/Zuck, Medizinrecht (Fußn. 4), § 13 Rdnr. 10 ff.; zum Rechtsverhältnis zwischen Patient und Krankenhaus im US-amerikanischen Recht Miller, Problems in Health Care Law (Fußn 4), S. 283 ff.

8 Für Krankenhäuser wird die Verpflichtung zur Krankenhausaufnahme in einigen deutschen Ländern ausdrücklich gesetzlich geregelt. Zur Frage einer Verpflichtung zur Krankenhausaufnahme im USamerikanischen Recht vgl. u.a. Furrow, Health Law (Fußn 4), S. 510 ff.; Showalter, Law of Healthcare Administration (Fußn 4), S. 159 ff.

9 Vgl. zur Verrechtlichung der Beziehungen zwischen Arzt und Patient, bei der v.a. früher oft betont wurde, sie gehe über juristische Vertragsbeziehungen hinaus, Uhlenbruck, in: Laufs/Uhlenbruck, Handbuch des Arztrechts, $\S 39$ Rdnr. 3 ff. 
diese Vorgaben konkretisiert werden. ${ }^{10}$ Auf diesem Wege wird zugleich die Implementierung der für das ärztliche Handeln bestehenden standesrechtlichen und staatlichen Regulierungen auch in die Hände der Vertragsparteien gelegt.

\subsection{Das Versicherungsverhältnis}

Das Behandlungsverhältnis zwischen Arzt bzw. Krankenhaus und Patient wird in der Praxis zumeist ergänzt um ein Versicherungsverhältnis zwischen Patient und einem Versicherungsträger. Weil das Krankheitsrisiko jeden Menschen trifft und der Eintritt des Krankheitsfalls mit hohen Kosten verbunden sein wird, besteht ein Interesse daran, durch Bündelung die mit dem Risiko für den Einzelnen verbundenen Folgen zu verteilen. Das ist die Grundidee der Versicherung: eine Gemeinschaft der Versicherten zu schaffen, die in der Lage ist, überdurchschnittliche Belastungen zu verteilen.

Eine Versicherung ist Vorsorge für die Realisierung eines Risikos. Der Versicherer verspricht eine teilweise oder völlige Übernahme der durch Eintritt des Versicherungsfalls entstehenden Schäden. Dafür zahlt der Versicherte Prämien. Sie sind Gegenleistungen für die Absicherung (Vorsorgeelement) und stehen damit zugleich in einem rechtlichen Zusammenhang zu den Zahlungen im Versicherungsfall (Kompensationselement). Ist die Versicherung als Ansparung für einen als wahrscheinlich gedachten Risikoeintritt gedacht wie in der Alterssicherung, tritt das Vorsorgeelement wertmäßig zurück und spielt für die Äquivalenz zwischen Prämie und Versicherungsleistung nur eine untergeordnete Rolle.

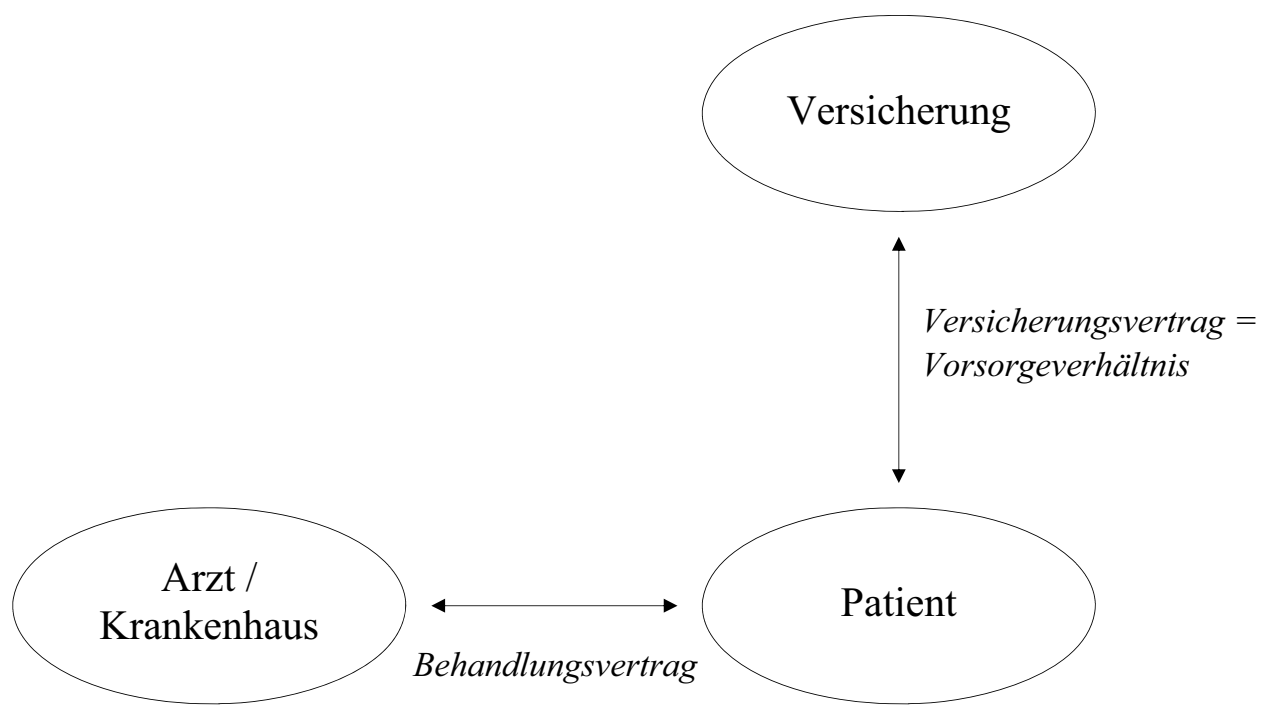

10 Vgl. dazu im Hinblick auf die Besonderheiten des Arzt-Patienten-Verhältnisses BVerfGE 52, 131 (zum Haftungsrecht und damit verbundenen Beweisanforderungen) 
Wird das Versicherungsverhältnis zwischen Versichertem und Versicherungsunternehmen abgeschlossen, ist es regelmäßig, wie das Behandlungsverhältnis, ein zivilrechtliches Rechtsverhältnis. ${ }^{11}$ Ein entsprechendes Versicherungsverhältnis kommt nach den allgemein geltenden Regelungen über den Abschluß von Verträgen zustande, sein Inhalt richtet sich nach den zugrundeliegenden Willenserklärungen - wenn auch in der Praxis durch zum Teil umfangreiche Regulierungen die Privatautonomie eingeschränkt wird (vgl. unten 2. a)).

Bezogen auf medizinische Behandlungen, erstattet ein privater Versicherungsträger regelmäßig die Kosten, die durch die Behandlungsleistungen entstehen (Kostenerstattungsprinzip). Er deckt also die für den Versicherten aus dem Behandlungsverhältnis folgenden Zahlungspflichten ab, weshalb das Versicherungsverhältnis als Deckungsverhältnis bezeichnet werden kann. Bei dieser Konstellation entstehen keine unmittelbaren Rechtsbeziehungen zwischen Versicherungsträger und Leistungserbringer. Denkbar ist allerdings, daß der Leistungserbringer vor allem bei teuren Behandlungen statt der unmittelbaren Zahlung durch den Versicherten eine Abtretung dessen Anspruchs aus dem Versicherungsverhältnis akzeptiert, die Abtretung anstelle der Erfüllung tritt. In diesem Fall können mittelbar die Absprachen aus dem Versicherungsverhältnis die vertraglichen Pflichten aus dem Behandlungsverhältnis berühren.

Darüber hinaus können Versicherungsunternehmen ein Interesse haben, mit den Erbringern von Behandlungsleistungen unmittelbar vertragliche Absprachen zu treffen. Dieses Interesse resultiert aus der Verpflichtung der Versicherungsträger zur Kostenerstattung. Lassen sich die Kosten der Behandlung reduzieren, so kommt dies im Ergebnis auch den Versicherungsträgern zugute. Zwar können diese ihre Kosten wiederum über die Prämien auf die Versicherten abwälzen. Da sie aber mit anderen Versicherungsunternehmen konkurrieren müssen, steht diese Möglichkeit unter der Bedingung, daß höhere Preise für die Versicherung auf dem Markt durchsetzbar sind. Diese hier nur angedeuteten Zusammenhänge sind der Hintergrund für die Einführung eines Care Managements.

\subsection{Das Sozialleistungs- und das Leistungserbringungsverhältnis}

Das Rechtsverhältnis zwischen Ärzten bzw. Krankenhäusern und Versicherern gewinnt an Bedeutung, wenn statt einer Privatversicherung eine Sozialversicherung die Risikoabsicherung übernimmt. Sozialversicherungen zeichnen sich durch Versicherungszwang und Beitragsfinanzierung aus, wobei Finanzierungsverfahren und Ausgleichswirkungen hier außer Betracht bleiben. ${ }^{12}$ An die Stelle des privatrechtlichen

11 Das ist nicht nur historisch, sondern selbst nach der Anerkennung öffentlich-rechtlicher Vertragsbeziehungen in den kontinentalen Rechtsordnungen auch normativ betrachtet der Ausgangspunkt.

$12 \mathrm{Vgl}$. zu den Charakteristika einer sozialen Tätigkeit in Unterscheidung von einer unternehmerischen nur EuGH v. 17.2.1993, Rs. C-159 u. 160/91 (Poucet u.a./Assurances générales de France u.a. - Sozialversicherung für Selbständige), Slg. 1993, S. I-637, Rdnr. 8, 10, 13, 18; EuGH v. 21.9.1999, u.a. 
Versicherungsvertrags rückt ein öffentlich-rechtliches Sozialleistungsverhältnis. Leistungsgrund bleibt zwar die Vorsorge, das Gegenseitigkeitsverhältnis zwischen Beiträgen und Leistungen ist aber nicht nur in Bezug auf die jeweilige Wertigkeit unterbrochen. ${ }^{13}$ In den meisten Staaten, die eine soziale Krankenversicherung eingeführt haben, bestehen gesetzliche Regeln über eine klare Zuständigkeitsverteilung. Wahlmöglichkeiten der Versicherten sind die Ausnahme, die allerdings für das hier verfolgte Projekt eine besondere Bedeutung besitzt. ${ }^{14}$

Innerhalb der Kategorie der sozialen Krankenversicherung kann zwischen zwei Arten unterschieden werden, soweit es die Art der jeweils versprochenen Sozialleistungen betrifft: Nämlich zwischen Systemen, die wie die Privatversicherung Kostenerstattung vorsehen, ${ }^{15}$ und solchen, die auf dem Sachleistungsprinzip beruhen. ${ }^{16}$ Sachleistungsprinzip bedeutet, daß die Krankenversicherung die zur Behandlung notwendigen Dienst- und Sachleistungen dem Versicherten verspricht (im Sozialversicherungs- oder allgemeiner im Sozialleistungs- bzw. Vorsorgeverhältnis). Ärzte und Krankenhäuser werden Leistungserbringer. Sie übernehmen die Behandlung der Versicherten und damit die Erfüllung der aus dem Sozialleistungsverhältnis folgenden Leistungsansprüche (Erfüllungsverhältnis). Sie tun dies aber zugleich für und auf Kosten der Sozialversicherung. Die Abrechnung erfolgt deshalb unmittelbar zwischen ihnen und den Versicherungsträgern. Der Versicherte muß sich darum nicht kümmern. In entsprechenden Systemen bestehen also neben den beiden genannten Rechtsverhältnissen zusätzlich Rechtsverhältnisse zwischen den Leistungserbringern, etwa den Ärzten und Krankenhäusern, einerseits und den Trägern der Sozialversicherung andererseits (Beschaffungsverhältnis). Diese sind nicht auf die Zahlung beschränkt. Vielmehr muß auch der Zugang der Versicherten zu den Leistungserbringern gesichert werden, ferner sind Vorkehrungen zur Mengensteuerung und zur Qualitätssicherung erforderlich. Um die Leistungserbringer an diese Vorgaben zu binden, bedarf es eines rechtlichen Akts der Einbeziehung; sei es in Form eines einseitigen Zulassungsakts oder in Form eines Vertragsabschlusses.

Wer für die Einbeziehung der Leistungserbringer und die Regulierung der rechtlichen Beziehungen zwischen Leistungserbringern und Versicherungsträgern zuständig ist, kann je nach Ausgestaltung unterschiedlich sein. Sind die Versicherungsträger verselbständigt, besitzen sie insbesondere eine eigene Rechtspersönlichkeit, ${ }^{17}$ ist zwischen

C-219/97 (Maatschappij Drijvende Bokken BV/Stichting Pensioenfonds voor de Vervoeren Havenbedrijven - Betriebsrenten), Slg. 1999, S. I- 6121, Rdnr. 67 ff.; EuGH v. 22.1.2002, Rs. C-218/00 (Cisal/INAIL - gesetzliche Unfallversicherung), Slg. 2002, S. I-691, Rdnr. 34 ff.

13 Es dürfte der Regel entsprechen, daß die tatsächliche Beitragszahlung nicht Leistungsvoraussetzung ist; vgl. zu diesem in Italien auch als ,principio della automaticità “ bezeichneten Grundsatz Cannella, Lezioni di diritto della previdenza sociale, 1975, S. $112 \mathrm{f}$.

14 Dazu unten, IV.2.

15 So in Belgien, Luxemburg und Frankreich.

16 So etwa in Deutschland, den Niederlanden und Österreich.

17 Dazu Becker, Staat und autonome Träger im Sozialleistungsrecht, 1996 
deren Handeln und dem des Staates zu unterscheiden. Dann kann der Staat gesetzliche Vorgaben setzen ${ }^{18}$ und den Trägern bei deren Ausfüllung Gestaltungsspielräume überlassen. Das ermöglicht unter Umständen den Abschluß von Einzelverträgen mit Leistungserbringern oder das Setzen generell-abstrakter Regelungen im Rahmen neokorporatistischer Arrangements. ${ }^{19}$

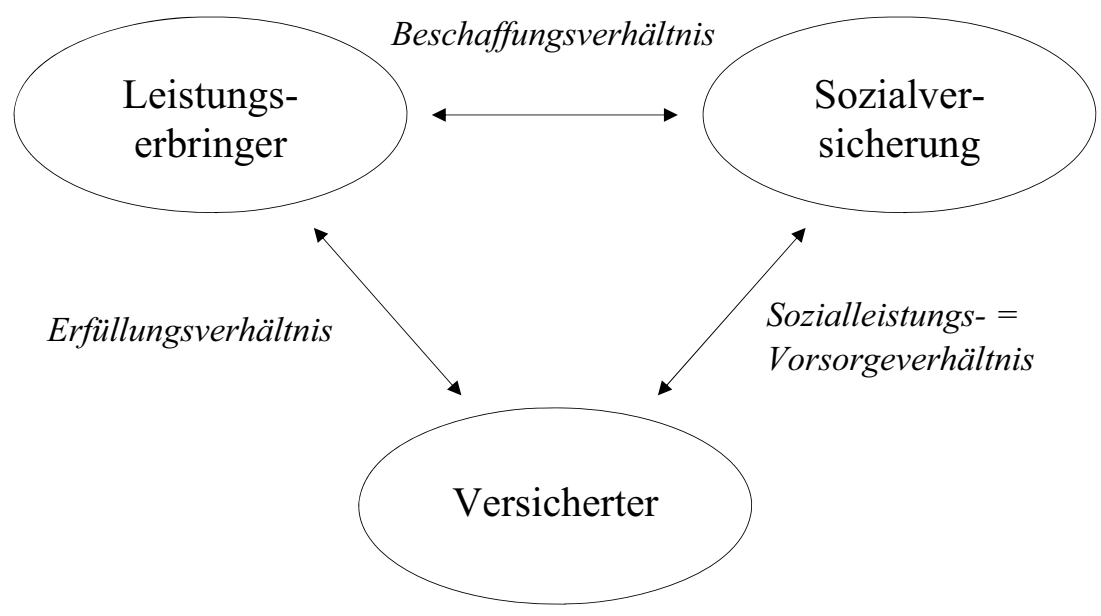

Rechtsbeziehungen zwischen Sozialversicherungsträgern und Leistungserbringern finden sich nicht nur in Sozialversicherungssystemen, die dem Sachleistungsgrundsatz folgen. Eine Kostenerstattung erübrigt nämlich nicht von vornherein, Vorkehrungen zur Sicherung und Steuerung von Zugang, Preis und Qualität der medizinischen Behandlungsleistungen zu treffen. Im Gegenteil: Weil Sozialversicherungen auf Zwang beruhen, ist der Staat für deren Funktionieren verantwortlich. Er muß sich also um das Vorhandensein der erforderlichen Infrastruktur, die Einbeziehung von Leistungserbringern und die Einhaltung einer guten Behandlungspraxis kümmern. ${ }^{20}$ Nichts anderes gilt im übrigen im Rahmen von nationalen Gesundheitsdiensten. In diesen (zumindest hauptsächlich) durch Steuermitteln finanzierten Systemen fehlt es zwar an rechtlich selbständigen Trägern, nicht aber an Behörden mit einem gewissen Handlungsspielraum. Vor allem ist es keineswegs zwangsläufig, daß in Gesundheitsdiensten die Leistungen durch deren eigene Einrichtungen und angestellte Ärzte erbracht werden. ${ }^{21}$ Vielmehr beziehen auch viele Gesundheitsdienste die Ärzte und andere Leistungserbringer, die grund-

$18 \mathrm{Zu}$ dessen Regulierungstätigkeit unten, III.2.a).

19 Dazu unten III.2..2.

20 Vgl. zum französischen Krankenversicherungsrecht nur Dupeyroux u.a., Droit de la sécurité sociale, 15. Aufl. 2005, S. $499 \mathrm{ff}$.

21 Vgl. zu den Ärzten im Rahmen des englischen National Health Service nur Fahlbusch, Ambulante ärztliche Behandlung in Europa, 2006, S. 170 ff. 
sätzlich selbständig tätig werden, durch vertragliche Absprachen in die Erfüllung ihrer Aufgaben ein.

\section{Erweiterungen}

\subsection{Die Rolle des Staates: Regulierungen}

Soweit soziale Krankenversicherungen oder Gesundheitsdienste eingerichtet worden sind, beruhen diese auf gesetzlichen Grundlagen. Welche Fragen durch die Parlamente entschieden werden müssen, richtet sich allerdings nach den jeweiligen verfassungsrechtlichen Vorgaben. Diese sind auch in Staaten, die das Demokratieprinzip zur Grundlage haben, unterschiedlich. Entsprechend weicht die Verteilung zwischen parlamentarischer und exekutiver Rechtsetzung von Rechtsordnung zu Rechtsordnung voneinander $a b$, und selbst für die Notwendigkeit von Außenrechtssätzen überhaupt gibt es keine allgemeingültigen Regeln. ${ }^{22}$ In jedem Fall wird aber das Sozialrecht durch weitere Gesetze ergänzt, die sich nicht spezifisch das Funktionieren der Sozialleistungssysteme zum Gegenstand haben, sondern allgemeiner die Tätigkeit aller Erbringer von medizinischen Leistungen betreffen. Bei ihnen handelt es sich um Regulierungen im Sinne gesetzlicher Maßnahmen, die der Ordnung privatautonomen Handelns dienen. Entsprechende Regulierungen beziehen sich einerseits auf das Versicherungswesen, andererseits auf bestimmte Teile der Gesundheitsversorgung. Soweit sie gesundheitsspezifisch sind, gehören sie zum Recht des Gesundheitswesens im weiteren Sinn.

2.1.1. In den meisten Rechtsordnungen ist die privatautonome Gestaltungsfreiheit für Versicherungsverträge durch staatliche Regulierungen eingeschränkt. ${ }^{23}$ Hinter entsprechenden versicherungsrechtlichen Vorgaben ${ }^{24}$ steht das Ziel der Ordnung des Wirt-

22 So enthalten die gesetzlichen Grundlagen des englischen National Health Service keinen Leistungskatalog, sondern nur programmatische und damit ausfüllungsbedürftige Vorgaben, vgl. nur Montgomery, Health Care Law, 2. Aufl. 2003, S. 51 ff.

23 Für Europa genügt es in diesem Zusammenhang, auf die Harmonisierungsvorschriften der Europäischen Gemeinschaft hinzuweisen, insbesondere die Richtlinien Schadenversicherung: RL 73/239/EWG zur Koordinierung der Rechts- und Verwaltungsvorschriften betreffend die Aufnahme und Ausübung der Tätigkeit der Direktversicherung (mit Ausnahme der Lebensversicherung) (ABl. 1973 Nr. L 228/3), 2. RL 88/357/EWG zur Koordinierung der Rechts- und Verwaltungsvorschriften für die Direktversicherung (mit Ausnahme der Lebensversicherung) und zur Erleichterung der tatsächlichen Ausübung des freien Dienstleistungsverkehrs (ABl. 1988 Nr. L 172/1) und RL 92/49/EWG zur Koordinierung der Rechts- und Verwaltungsvorschriften für die Direktversicherung (mit Ausnahme der Lebensversicherung) (ABl. 1992 Nr. L 228/1); vgl. allgemein auch Roth, Internationales Versicherungsvertragsrecht, 1985, S. 169 ff.

24 Dazu kommen allgemeine Vorgaben für Massenverträge, etwa in Form der Inhaltskontrolle von Allgemeinen Geschäftsbedingungen und in Form der Abschlußkontrolle bei bestimmten Vertriebswegen. 
schaftslebens im allgemeinen bzw. das des Verbraucherschutzes im besonderen, weil die Versicherungsnehmer aufgrund ihrer relativ schwachen wirtschaftlichen Stellung und unvollständiger Informationen nicht in der Lage sein werden, ihre Interessen allein in ausreichendem Maße wahrzunehmen.

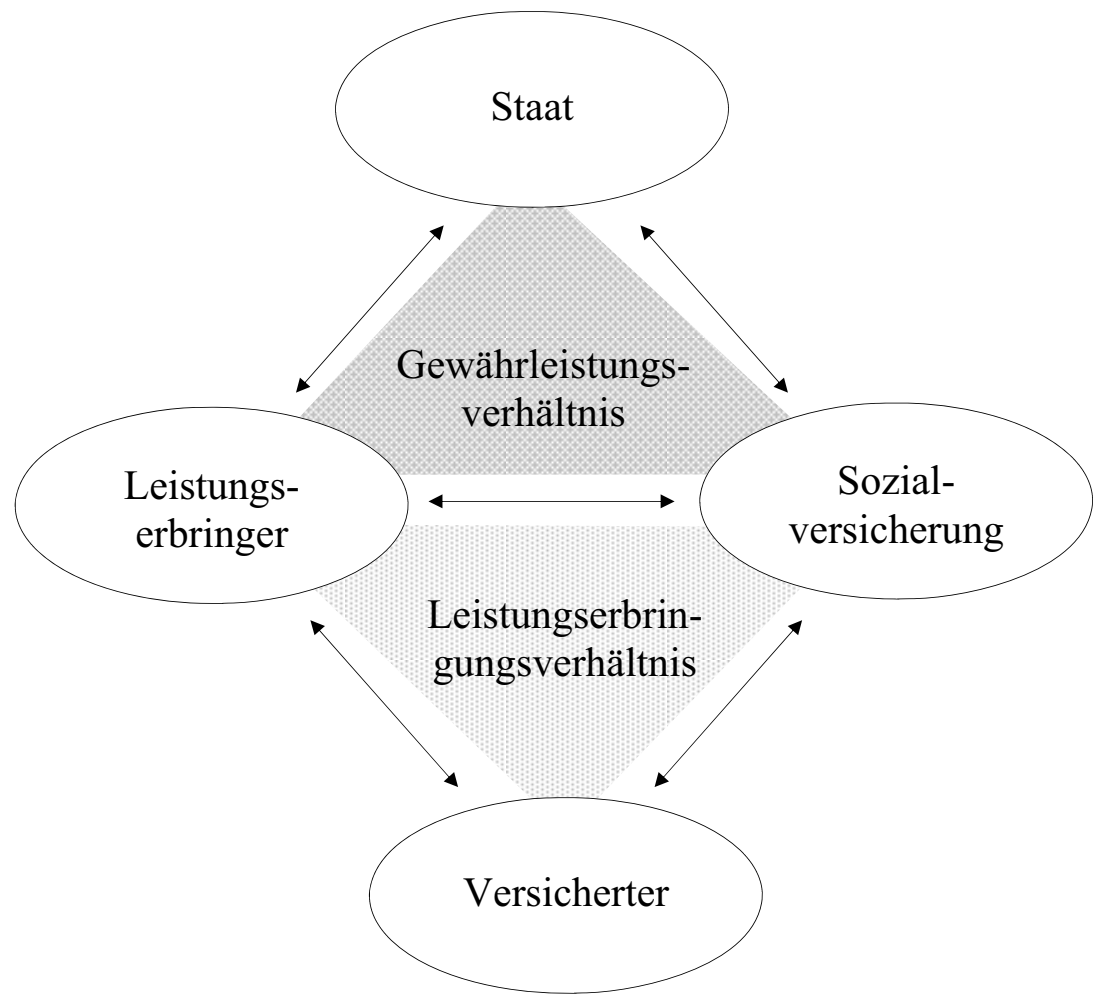

2.1.2. Weitere Regulierungen betreffen die im Rahmen von ärztlichen Behandlungen durchgeführten oder verordneten Sachmittel und Dienstleistungen, seien es Arznei- und Hilfsmittel oder die unterstützenden Tätigkeiten von Therapeuten. ${ }^{25}$ Für die Gesundheitsdienstleistungen existieren zum einen besondere Ausbildungsvorschriften, die im Rahmen der Europäischen Union zur Herstellung der Freizügigkeit harmonisiert worden sind. ${ }^{26}$ Dazu kommen berufsrechtliche Vorschriften, die insbesondere die ärztliche Tätigkeit in den meisten Staaten in geordnete Bahnen lenken sollen. Bei Sachmitteln steht die Gewährleistung der Produktsicherheit im Vordergrund. Hinzuweisen ist nur auf die europäischen Vorschriften für Arzneimittel ${ }^{27}$ oder für Medizinprodukte ${ }^{28}$. Diese Vor-

25 Überblick zu den „Nebengesetzen“ für die Leistungserbringung in Deutschland bei Becker/Kingreen, Einführung, in: SGB V, Öffentliches Gesundheitswesen, 15. Aufl. 2008, S. XXIV ff.

26 Überblick dazu bei Becker, in: Schnapp/Wigge (Hrsg.), Handbuch des Vertragsarztrechts, 2. Aufl. 2006, § 25 Rdnr. 1 ff.

27 Auf die Richtlinien zur Schaffung jeweils eines Gemeinschaftskodexes für Humanarzneimittel (RL 2001/83, ABl. 2001 Nr. L 311/67) und für Tierarzneimittel (RL 2001/82, ABl. 2001 Nr. L 311/1), die durch weitere Vorschriften über Farbstoffe, Versuche, Handel und spezielle Arzneimittel er- 
schriften werden ergänzt durch Vertriebsbeschränkungen, zu denen etwa das deutsche Apothekenmonopol gehört. ${ }^{29}$ Schließlich kann die Bereitstellung der für die Versorgung erforderlichen Infrastruktur planungsrechtlichen Bestimmungen unterliegen.

\subsection{Mögliche Zwischenebene: Korporatistische Arrangements}

Die Steuerung von Gesundheitsleistungen kann nicht nur staatlicher Rechtsetzung oder dem Wettbewerb überlassen werden, sondern auf einer Zwischenebene auch durch einen korporatistischen Interessenausgleich erfolgen. ${ }^{30}$ Dafür müssen Verbände sowohl auf Seiten der Versicherungsträger als auch der Leistungserbringer die Funktion übernehmen, das Verhalten ihrer Mitglieder so zu lenken, daß es für bestimmte Belange den gesamtgesellschaftlichen Erfordernissen entspricht. ${ }^{31}$ Dieses System beruht einerseits auf einer Anerkennung gesellschaftlicher Interessen, verbunden mit der Gewährung von Rechten und Privilegien an deren Organisationen, andererseits auf einer Instrumentalisierung dieser Organisationen zu Zwecken staatlicher Politik. ${ }^{32}$ In Deutschland erfolgt ein Aushandeln der Bedingungen für die ärztlichen Leistungen im Wege der sog. gemeinsamen Selbstverwaltung. 33

Zum einen hat der Gesetzgeber eigene Einrichtungen geschaffen, in denen die Versicherungsträger und die Leistungserbringer zusammenarbeiten. Das Sozialgerichtsgesetz verwendet dafür den Begriff der „gemeinsamen Gremien“. 34 In der Sache handelt es sich um eine doppelte Verselbständigung in Form eines Ausschußmodells. Die praktisch wichtigsten Einrichtungen sind in dieser Hinsicht mittlerweile der Gemeinsame Bundesausschuß, der zentrale Fragen der Gesundheitsversorgung durch den Erlaß von

gänzt werden, ferner auf die Schaffung eines Gemeinschaftsverfahrens für die Genehmigung und Überwachung durch VO 726/2004 (ABl. 2004 Nr. L 136/1).

28 RL 93/42/EWG v. 14.6.1993 über Medizinprodukte (AB1. 1993 Nr. L 169/1).

29 Dazu Becker, Lockerung des Mehr- und Fremdbesitzverbots von Apotheken im Lichte des Grundgesetzes und der Grundfreiheiten des EG-Vertrags, in: Mand (Hrsg.), Neuregelung des Apothekenrechts, Frankfurt a.M. 2004, S. 48 ff. m.w.N. Die Vereinbarkeit des Monopols mit europäischem Gemeinschaftsrecht ist Gegenstand eines Vorabentscheidungsverfahrens, vgl. SA des GA Bot in der Rs. C-171/07 u. C-172/07 v. 16.12.2008 (Apothekerkammer des Saarlandes u.a.), n.v.

30 Vgl. Becker, Gesetzliche Krankenversicherung zwischen Markt und Regulierung, JZ 1997, S. 534 ff.

31 Vgl. zu dem Zusammenhang zwischen sektoral beschränkter Funktion der Verbände und einem erfolgreichen Vermittlungsprozeß Böckenförde, Die politische Funktion wirtschaftlich-sozialer Verbände und Interessenträger in der sozialstaatlichen Demokratie, Der Staat 15 (1976), S. 457, 476 ff.

32 Zum „Hineinwachsen privatrechtlicher Organisationen in einen Bereich gesteigerter öffentlicher Bedeutung“ Schuppert, Die Erfüllung öffentlicher Aufgaben durch verselbständigte Verwaltungseinheiten, 1981, S. $96 \mathrm{ff}$.

33 Vgl. Becker, Hat die gemeinsame Selbstverwaltung noch eine Zukunft?, in: 7. Münsterische Sozialrechtstagung: Gesetzliche Krankenversicherung in der Krise - Von der staatlichen Regulierung zur solidarischen Wettbewerbsordnung, 2002, S. 122 ff. m.w.N.

$34 \S 51$ II 1 Nr. 2 SGG. 
Richtlinien feinsteuert ${ }^{35}$ und damit zu dem mächtigsten Akteur im Gesundheitswesen geworden ist, dessen demokratische Legitimation sehr umstritten ist. ${ }^{36}$

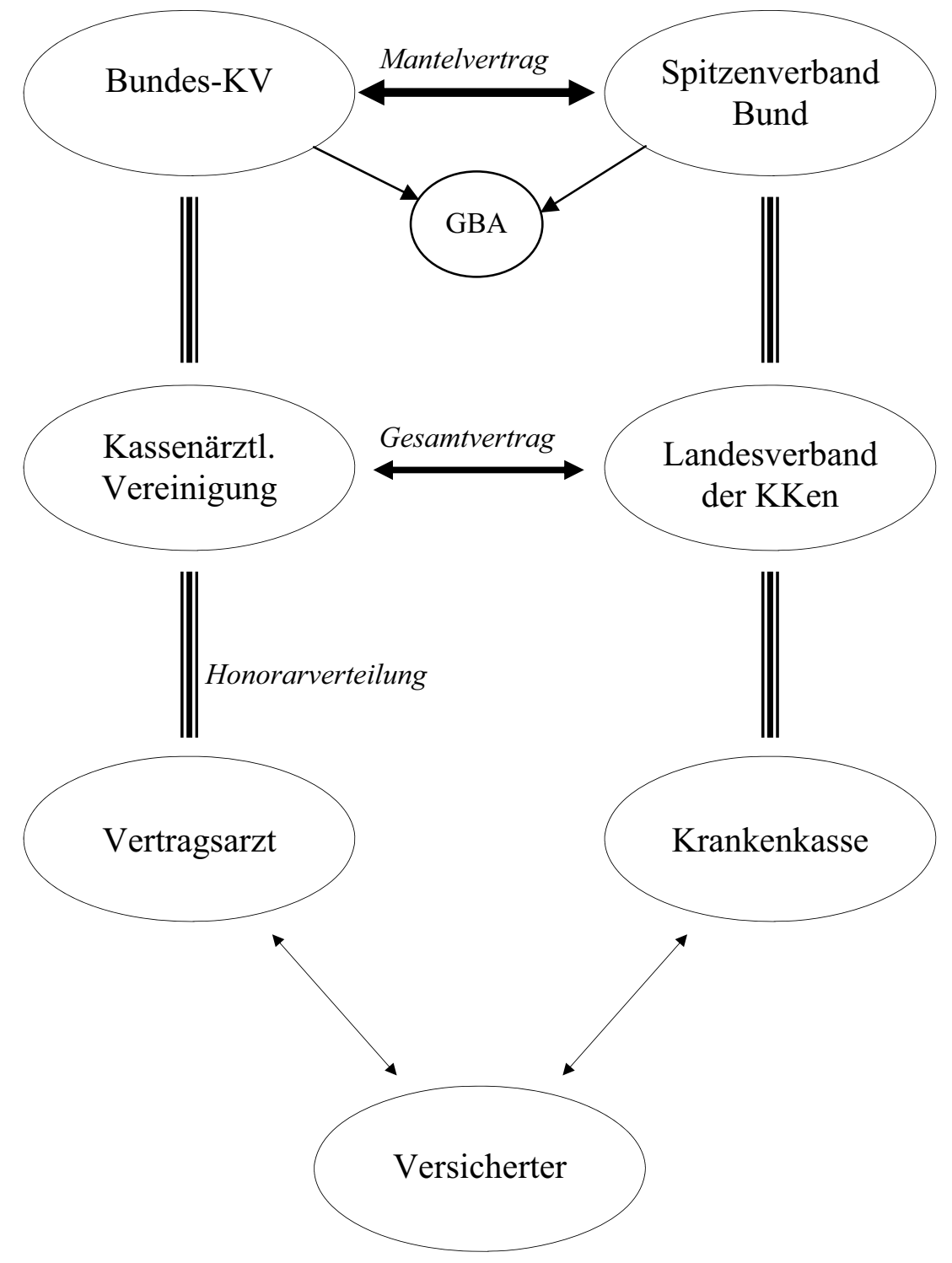

Die zweite Form der gemeinsamen Selbstverwaltung besteht im Aushandeln von Verträgen, die je nach Ebene Bewertungsmaßstäbe und Grundsätze für die Durchfüh-

35 Vgl. § 92 SGB V. Die Bedeutung der Richtlinien liegt in der Zuerkennung normativer Wirkung, dazu nur Axer, Normsetzung in der Sozialversicherung, 2000, S. 115 ff. und 148 ff.

36 Vgl. nur Butzer/Kaltenborn, Die demokratische Legitimation des Bundesausschusses der Ärzte und Krankenkassen, MedR 2001, S. 333 ff.; Kingreen, Legitimation und Partizipation im Gesundheitswesen - verfassungsrechtliche Kritik und Reform des Gemeinsamen Bundesausschusses, NZS 2007, S. $113 \mathrm{ff}$. 
rung der Versorgung enthalten - so die Bundesmantelverträge ${ }^{37}$ - oder vor allem die Vergütung festlegen - so die Gesamtverträge auf Landesebene. ${ }^{38}$ Insofern wird prinzipiell auf eine gesonderte institutionelle Verklammerung verzichtet - der Bewertungsausschuß $\beta^{39}$ gehört wiederum zur vorgenannten Form institutioneller Verselbständigung. ${ }^{40}$ Allerdings kommt auch das Vertragswesen selbst nicht ohne eigene Einrichtungen aus. Es kann zum einen solche Einrichtungen schaffen. ${ }^{41}$ Zum anderen muß für den Fall, daß sich die Parteien nicht über die erforderlichen Inhalte der Verträge einigen können, ein Schiedsamt den Vertragsinhalt festsetzen. ${ }^{42}$ Dessen Zusammensetzung entspricht wieder dem für die genannten Ausschüsse verwendeten Modell: Die Ämter setzen sich aus drei unparteiischen Mitgliedern sowie Vertretern der Ärzte und der Krankenkassen zusammen, wobei die Zahl der Interessenvertreter nicht durch Gesetz, sondern durch Rechtsverordnung bestimmt ist. ${ }^{43}$ Insgesamt läßt die Ausgestaltung eine Unterteilung in Stufen erkennen, auf denen das Verhältnis zwischen Kassen und Leistungserbringern geregelt wird, wobei je nach Einteilung eine zweite oder eine dritte Stufe das „,konkrete Lieferungs- und Abrechnungsverhältnis zwischen den zugelassenen Leistungserbringern und der Kasse" betrifft. ${ }^{44}$

\subsection{Die Rolle der Arbeitgeber}

Schließlich ist kurz auf die Rolle der Arbeitgeber einzugehen, die das Leistungsdreieck, das sich als vollständiges oder unvollständiges bei Vorhandensein einer Krankenversicherung ergibt, in unterschiedlicher Form ergänzen.

In den Staaten, die über eine soziale Krankenversicherung verfügen, ist diese Rolle eine sehr eingeschränkte. In einigen Ländern fungieren die Arbeitgeber noch als Beitragspflichtige und möglicherweise auch als Beitragszahler. ${ }^{45}$ Zudem trifft sie oft eine

$37 \S 82 \mathrm{I}, 87 \mathrm{SGB} \mathrm{V}$.

$38 \S \S 82 \mathrm{II}, 83 \mathrm{ff}$. SGB V.

39 Zur Zusammensetzung § 87 III SGB V.

40 Vgl. zu dessen Tätigkeit BSG v. 16.5.2001, B 6 KA 20/00 R.

41 Vgl. etwa zum Prothetik-Einigungsausschuß BSG, SozR 3-1500 § 78 Nr. 5. Vgl. auch die gemeinsamen Prüfungs- und Beschwerdeausschüsse nach $\S 106$ IV SGB V.

42 Vgl. § 89 SGB V. Die Schiedsämter werden als eigene (beteiligungsfähige) Behörden ohne eigene Rechtspersönlichkeit angesehen, vgl. zur verfahrensrechtlichen Stellung BSGE 86, 126 = SozR 32500 § 85 Nr. 37; zur Pflegeversicherung zuletzt BSGE 87, 199.

43 Schiedsamtsverordnung v. 28.5.1957 (BGB1. I, S. 570 m.Änd.). Auf die Schiedsämter wird im folgenden nicht näher eingegangen; vgl. allgemein Hofmann, Das Schiedsamt im Kassenarztrecht nach dem Sozialgesetzbuch Teil V, 1991; Düring, Das Schiedswesen in der gesetzlichen Krankenversicherung, 1992.

44 v. Maydell, Leistungsbeschaffung (insbesondere von Heil- und Hilfsmitteln) durch die gesetzlichen Krankenkassen zwischen öffentlichem und privatem Recht, DB 1985, S. 276, 280.

45 In Deutschland mit der Folge der Beteiligung an der sozialen Selbstverwaltung; krit. dazu Schulin, Rechtliche Grundprinzipien der gesetzlichen Krankenversicherung und ihre Probleme, in: HS-KV, 1994, § 6, Rdnr. 89 ff. 
Verpflichtung zur Entgeltfortzahlung im Krankheitsfall. ${ }^{46}$ Reste einer stärkeren Verantwortung der Arbeitgeber finden sich in den deutschen Vorschriften über die Betriebskrankenkassen. ${ }^{47}$ Diese sind Nachfolger der früheren Fabrikkrankenkassen. Bei Beginn der deutschen gesetzlichen Krankenversicherung konnten die Arbeitgeber verpflichtet werden, entsprechende Versicherungsträger für ihren Betrieb zu errichten. ${ }^{48}$ Das war Ausdruck des Umstands, daß die Tätigkeit in vielen Betrieben mit besonderen Gesundheitsgefahren verbunden war und sicherte den Arbeitgebern zugleich einen großen Einfluß. Nach Einführung des Kassenwettbewerbs in den 1990er Jahren ${ }^{49}$ konnten sich Betriebskrankenkassen öffnen und damit ihre Funktion als Versicherungsträger für die Angehörigen eines bestimmten Betriebs aufgeben. ${ }^{50}$ Davon haben viele Betriebskrankenkassen Gebrauch gemacht. ${ }^{51}$ Dennoch existieren bis heute geschlossene Betriebskrankenkassen, 52 in denen nur Mitarbeiter der Trägerunternehmen versichert werden können. 53

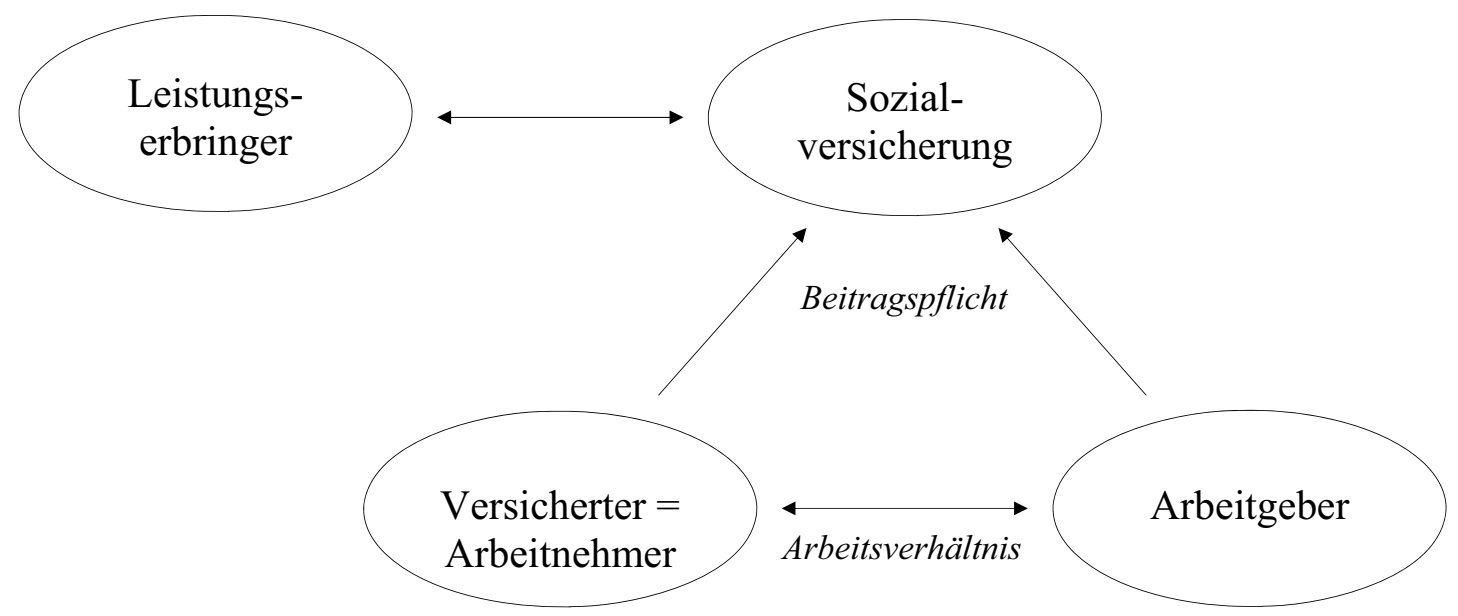

46 Die damit regelmäßig funktional äquivalent zu den Lohnersatzleistungen der (Sozial-)Versicherungen ist.

$47 \S 147$ ff. SGB V.

48 Vgl. dazu Stier-Somlo, Deutsche Sozialgesetzgebung, geschichtliche Grundlagen und Krankenversicherungsrecht, 1906, S. $215 \mathrm{ff}$.

49 Vgl. dazu unten, IV.2.a).

50 Auf der Grundlage des $\S 173$ Abs. 2 S. 1 Nr. 4 SGB V.

51 Wie auch ein starker Konzentrationsprozeß zu verzeichnen ist. So hat die Zahl der BKK von über $1.100 \mathrm{im}$ Jahr 1970 auf $169 \mathrm{im}$ Jahr 2008 abgenommen, vgl. die Informationen auf http://www.bmg.bund.de.

52 Zur Zet ca. 40 BKK, vgl. die Informationen bei http://www.bkk.de.

53 Durch das GKV-WSG sollte diese Möglichkeit im Sinne der Ausweitung des Wettbewerbs aufgegeben werden, jedoch wurde ein entsprechender Entwurf nicht umgesetzt, vgl. Just, in: Becker/Kingreen (Hrsg.), SGB V, 2008, § 173 Rdnr. 7. 
In den USA kommt den Arbeitgebern nach wie vor eine sehr viel gewichtigere Rolle im Rahmen der Krankenversicherung zu. ${ }^{54}$ Denn in der Regel wird Arbeitnehmern von ihren Arbeitgebern ein Versicherungsangebot unterbreitet, die Arbeitgeber tragen zur Finanzierung entsprechender Versicherungen, die bei kommerziellen oder gemeinnützigen Unternehmen abgeschlossen werden können und als Gruppenversicherungen vergünstigte Prämien gegenüber einem individuellen Versicherungsschutz vorsehen, bei. Wie schon erwähnt, ${ }^{55}$ haben Versicherer und wegen ihres finanziellen Engagements auch die Arbeitgeber ein Interesse daran, Versicherungs- und Leistungserbringungsverhältnis im Wege des managed care miteinander zu verknüpfen, um auf diese Weise auf die Kosten und die Qualität der medizinischen Behandlungen Einfluß zu nehmen.

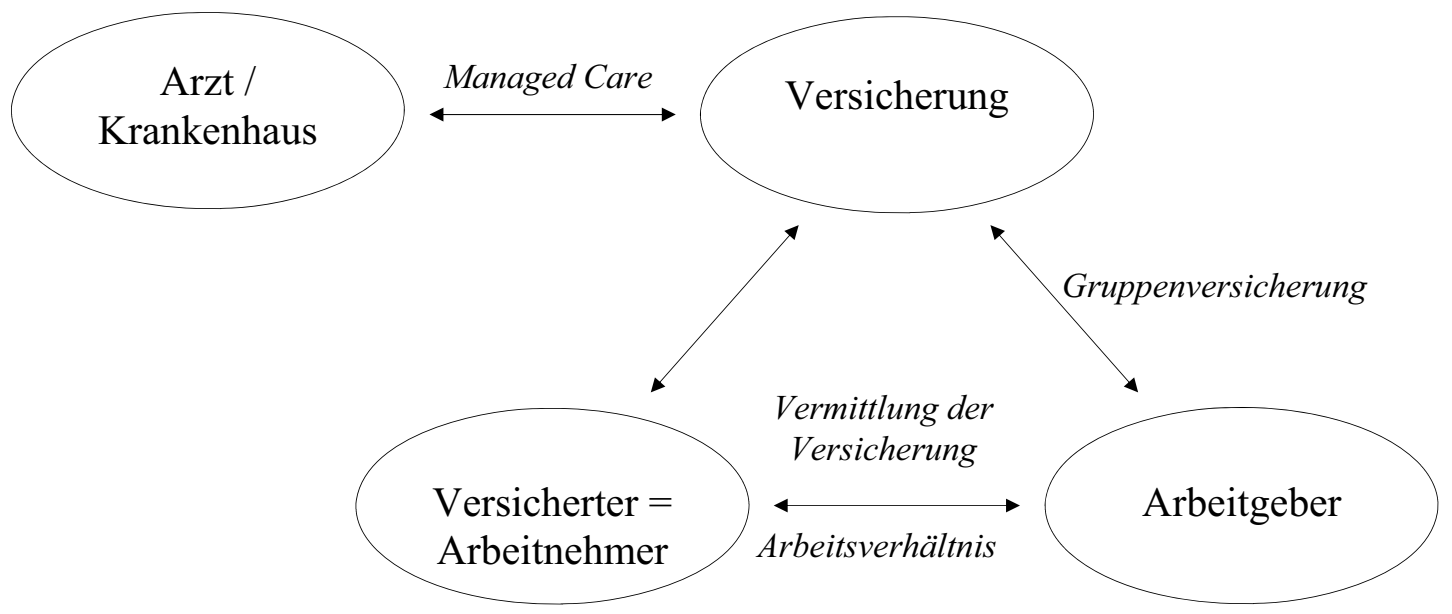

\section{Wettbewerb und Gesundheitsleistungen- theoretische Vorüberlegungen zu Wahlmöglichkeiten und deren Steue- rung}

\section{Zu den Funktionen von Wettbewerb und Sozialleistungssystemen}

\subsection{Ausgangspunkte}

1.1.1. Das Soziale ist, um es neutral zu formulieren, ein offener Begriff. Bei seiner Klärung mag man zwar nicht unbedingt in ,einen Morast der Verirrung“ geraten ${ }^{56}$, aber

54 Vgl. dazu Kruse, Das Krankenversicherungssystem der USA, 1997, S. 58 ff.

55 Vgl. oben, II.1.2.

56 So v. Hayek, Recht, Gesetz und Freiheit (Das Trugbild sozialer Gerechtigkeit), 2003, S. 229. 
doch in die Gefahr, sich im Allgemeinen zu verlieren. Denn zunächst läßt sich das Soziale am treffendsten negativ als Abgrenzung zum Individuellen verstehen. Das schließt Interaktionen zwischen Gesellschaftsmitgliedern ein, und eine Verknüpfung mit dem Wettbewerb kann über das „soziale Handeln“ hergestellt werden. Dieses Handeln ist auf das ,erwartete Verhalten anderer" bezogen. ${ }^{57}$ Wettbewerb dient der Verteilung knapper Güter, auf Märkten meint er die Inbezugnahme auf das Verhalten anderer Tauschinteressenten. ${ }^{58}$ In diesem Sinne stellt der Wettbewerb eine Form sozialen Handelns dar.

Ähnlich lassen sich die Zusammenhänge aus juristischer Perspektive beschreiben. Im 19. Jahrhundert verwendete Hermann Roesler den Begriff des "sozialen Rechts“ und verstand dieses als „Regel der gesellschaftlichen Freiheit“.59 Gegenübergestellt wurde die „Regel der menschlichen Freiheit“. Diese Unterscheidung entspricht der Otto von Gierkes zwischen Individualrecht und Sozialrecht, wonach unter dem Sozialrecht das Recht verstanden werden sollte, das ,die Beziehungen der menschlichen Willensträger als Einzelwesen zueinander in Beziehung setzt" ${ }^{60}$ Daraus folgt zunächst eine Unterscheidung zwischen individueller Freiheit und deren Gemeinschaftsgebundenheit, die auch Grundlage der später entwickelten und im folgenden aufzunehmenden Differenzierung zwischen Sozial- und Privatversicherung ist.

1.1.2. In dem Gemeinschaftsbezug des sozialen Rechts kommt zugleich ein Grundgedanke zum Ausdruck, der Sozial- und Wettbewerbsrecht gemeinsam ist: Nämlich die Zähmung privatautonomer Gestaltungsmacht, ${ }^{61}$ um deren Mißbrauch zu verhindern und die Wahrnehmung individueller Freiheit tatsächlich zu ermöglichen, also um die Grundlagen der Rechts- und Gesellschaftsordnung zu sichern. ${ }^{62}$ In diesem Sinne hat nicht nur das deutsche Privatrecht seinen „Tropfen sozialistischen Öls“63 erhalten, sondern sich nach langer Auseinandersetzung auch das Kartellrecht etabliert. 64 So gesehen

57 In der Definition von Max Weber, Wirtschaft und Gesellschaft (1922), 5. Aufl. 1972, S. 11 (Erster Teil, I. Soziologische Grundbegriffe, $\S 1$ II.).

58 Vgl. nur Homann/Suchanek, Ökonomik, 2. Aufl. 2005, S. 14. Zur „Konkurrenz“ als „friedlichem Kampf" Weber, a.a.O., S. 20.

59 Über die Grundlehren der von Adam Smith begründeten Volkswirtschaftstheorie, Ein Beitrag zur Rechtsphilosophie, 2. Aufl., 1868, S. 264; dazu näher Rauscher, Die soziale Rechtsidee und die Überwindung des wirtschaftsliberalen Denkens, Hermann Roesler und sein Beitrag zum Verständnis von Wirtschaft und Gesellschaft, 1969, S. $235 \mathrm{ff}$.

60 Deutsches Privatrecht, Bd. I, 1895, S. 26.

61 Roesler hat dementsprechend gemeint, die Freiheit des Privatwillens könne nicht geltend gemacht werden, wo es sich um die gemeinsamen Interessen des Kulturlebens handelt, wiedergegeben nach Rauscher, Die soziale Rechtsidee (Fußn. 59), S. 244.

62 Vgl. zu einer entsprechenden Vorstellung der „socialen Verwaltung“ auch Lorenz von Stein, Handbuch der Verwaltungslehre, 1876, S. $100 \mathrm{ff}$.

63 v. Gierke, Die soziale Aufgabe des Privatrechts, 1889, S. 13. Vgl. zu diesem näher Hofer, Freiheit ohne Grenzen, 2001, S. 141 ff. Zur Geschichte und Konzeption des Arbeitsvertrags und den privatrechtlichen und sozialpolitischen Hintergründen Rückert, „Frei“ und „,sozial“: ArbeitsvertragsKonzeptionen um 1900 zwischen Liberalismen und Sozialismen, ZfA 23 (1992), S. 225 ff.

64 Dazu und zur Rolle Franz Böhms die Abhandlung von Nörr, Die Leiden des Privatrechts, 1994. 
steht „das Soziale“ nicht in einem Gegensatz zum Wettbewerbsrecht. Denn die Privatautonomie ist zwar notwendige Grundlage des Wettbewerbs, aber die Geltung des Privatrechts allein garantiert noch nicht dessen Funktionieren. Entsprechend ist die Annahme Franz Böhms zu verstehen, die Institution Wettbewerb entfalte einen „sozialen Gesamteffekt". 65 Und auch umgekehrt berühren sich Soziales und Wettbewerb in ihrer Zielsetzung. Ein Hauptziel eines freiheitlich verfaßten Sozialstaates ist es, seinen Bürgern (und auch seinen Einwohnern) die Voraussetzungen der Eigenverantwortlichkeit zu garantieren. 66

1.1.3. Allerdings führen die Wege, die Sozialrecht und Wettbewerbsrecht zu ihren verschiedenen Zeiten der Entstehung eingeschlagen haben, in unterschiedliche Richtungen. Das Sozialrecht etablierte sich im Sinne der Umsetzung sozialpolitischer Zielsetzungen 67 als ein Rechtsgebiet mit besonderen Funktionen, nämlich als das Recht, das eine menschenwürdige Lebensgestaltung, ein dem Gleichheitssatz entsprechenden $\mathrm{Zu}$ gang zur gesellschaftlichen Teilhabe 68 und eine Absicherung gegen allgemeine Risiken 69 verwirklichen soll. Es bleiben die angesprochenen Überschneidungen mit dem Privatrecht, ${ }^{70}$ die Versuche, als ungerecht empfundene Tauschergebnisse durch Sonderrecht oder durch die Anwendung allgemeinerer Normen (insbesondere des Verfassungsrechts) zu korrigieren. 71

Das Sozialrecht als Kern des Sozialrechts läßt dem Markt wenig Raum, und zwar schon deshalb weil es sich auf dessen Ergebnisse gerade nicht verlassen will. Grund dafür sind die konzeptionellen Unterschiede zwischen Sozialem und Wettbewerb, wenn es darum geht, auf welche Weise die jeweiligen Ziele erreicht werden sollen. Sozialpolitik dient der Verfolgung von Gemeininteressen und beruht dementsprechend auf für

65 Dazu Nörr, Die Leiden des Privatrechts, 1994, S. 101 ff., 106.

66 Vgl dazu Kersting, Politische Solidarität statt Verteilungsgerechtigkeit?, in: ders. (Hrsg.), Politische Philosophie des Sozialstaats, 2000, S. 202, 237 ff., 247.

67 Zum Begriff der Sozialpolitik und seiner Entstehung F.X. Kaufmann, Der Begriff Sozialpolitik und seine wissenschaftliche Deutung, in: Geschichte der Sozialpolitik in Deutschland seit 1945, 2001, S. $3 \mathrm{ff}$.

68 Nicht hingegen zwangsläufig bereits die gleiche Teilhabe als solche.

69 Vgl. zu diesen Ausprägungen der Sozialstaatlichkeit Zacher, Sozialpolitik und Verfassung im ersten Jahrzehnt der Bundesrepublik Deutschland, 1970, S. 18 ff., 676 ff. (insb. 698 f.); ders., in: HStR Bd.2, 3. Aufl. 2004, S. 659, 678 (Rdnr. 2); Sommermann, in: v. Mangoldt/Klein/Starck (Hrsg.), GG Bd. 2, 5. Aufl. 2005, Art. 20 Rdnr. 103 ff. Zu einer ähnlichen Dreiteilung Atkinson, Poverty and Social Security, 1989, S. 100; Marshall, Bürgerrechte und soziale Klassen, Zur Soziologie des Wohlfahrtstaates, 1992, S. 40.

70 Dazu Felix, Die Rollenverteilung von öffentlichem und Privatrecht in der sozialen Sicherheit von heute, in: Soziale Sicherheit durch öffentliches und Privatrecht, SDSRV 51 (2003), S. 91, 98 ff.

71 Sehr kritisch zu dieser „Sozialisierung des Rechts“ unter der Beschreibung als „Umwandlung von Privatrecht in öffentliches Recht im Wege der ,Sozial'-Gesetzgebung" v. Hayek, Recht, Gesetz und Freiheit (Regeln und Ordnung), 2003, S. 145 ff. 
alle Gesellschaftsmitglieder verbindlichen und gleichen Werten, während das Wettbewerbshandeln durch individuelle subjektive Bewertungen ${ }^{72}$ gesteuert wird.

\subsection{Funktionen von sozialen Sicherungssystemen}

Mit Sozialleistungssystemen stellt der Staat bestimmte Güter zur Verfügung. In der Form der Sozialversicherungen sind sie geschaffen worden als Reaktion auf die soziale Frage des 19. Jahrhunderts. ${ }^{73} \mathrm{Da}$ für die konkrete Entstehung andere (darüber hinausgehende) Motive mindestens mit ausschlaggebend waren, 74 ändert an der Funktion der staatlichen Intervention, die wirtschaftlich schwache Stellung der Arbeiter zu verbessern, ${ }^{75}$ nichts.

Es ging und geht noch immer bei sozialer Sicherung im vorgenannten Sinn zugleich um eine Reaktion auf Marktversagen: ${ }^{76}$ zu Beginn auf die fehlenden Sicherungsmöglichkeiten für die auf ihre Arbeitskraft Angewiesenen im Falle von Krankheit und Erwerbsunfähigkeit sowie auf die unzulängliche Entschädigung im Falle von Arbeitsunfällen. ${ }^{77}$ Hier klingt die Schutzbedürftigkeit an, die nach wie vor - wenn auch offensichtlich keineswegs zureichend geklärt - in der allgemeinen Rechtfertigung für die

72 Zum subjektiven Werturteil als „Angelpunkt alles wirtschaftlichen Tun und Lassens der Menschen“ und dem Problem der Wertmessung Mises, Theorie des Geldes und der Umlaufmittel (2. Aufl. 1924), 2005, S. $10 \mathrm{ff}$.

73 Zur Entstehung nur Köhler/Zacher (Hrsg.), Ein Jahrhundert Sozialversicherung in der Bundesrepublik Deutschland, Frankreich, Großbritannien, Österreich und der Schweiz, 1981; Stolleis, Geschichte des Sozialrechts in Deutschland, 2003, S. 23 u. $36 \mathrm{ff}$.

74 Nämlich die Bekämpfung der Sozialdemokratie (dazu Tennstedt, Vorgeschichte und Entstehung der kaiserlichen Botschaft vom 17. November 1881, ZSR 1981, S. 663, 664 ; Hentschel, Geschichte der deutschen Sozialpolitik 1880 - 1980, 1983, S. 9 f.), die Stabilisierung des neuen Reiches im allgemeinen (vgl. zu den Zielen Bismarcks auch Pflanze, Bismarck, Der Reichskanzler, 1998, S. 409) und die passenden staatsphilosophischen Hintergründe (dazu Ritter, Der Sozialstaat, Entstehung und Entwicklung im internationalen Vergleich, 2. Aufl. 1991, S. 67 ff.; Stolleis, Die Entstehung des Interventionsstaates und das öffentliche Recht, ZNR 1989, S. 129, 131 ff.). Bismarck selbst (Fürst Bismarcks Reden, hrsg. von Ph. Stein, 10. Bd.: Kolonial-, Social- und Wirtschaftspolitik, 1884 1885) hat die innenpolitischen Zusammenhänge wie folgt beschrieben: „Wenn es keine Socialdemokratie gäbe, und wenn nicht eine Menge Leute sich vor ihr fürchteten, würden die mäßigen Fortschrite, die wir überhaupt in der Socialreform bisher gemacht haben, auch noch nicht existieren, und insofern ist die Furcht vor der Socialdemokratie in Bezug auf denjenigen, der sonst kein Herz für seine armen Mitbürger hat, ein ganz nützliches Element.“

$75 \mathrm{Zu}$ dieser sozialen Frage Eucken, Die soziale Frage, in: Festgabe für A. Weber, 1948, S. 113.

76 Vgl. auch Barr, The Economics of the Welfare State, 3. Aufl. 1998, S. $124 \mathrm{f}$.

77 Wobei schon zu Beginn die Frage sehr umstritten war, ob eine umfassende Sicherung (und zwar konkret gegen Arbeitsunfälle) privaten Unternehmen anvertraut werden konnte, vgl. dazu näher Vogel, Bismarcks Arbeiterversicherung, 1951, S. 152 ff. Berühmt wurde Bismarcks Warnung vor einer privatrechtlichen Ausgestaltung mit dem Ausspruch ,nur keine private Anstalt mit Dividende und Konkurs“, Marginalie Bismarcks auf einer Denkschrift der bayerischen Regierung v. 31.12.1881, Quellensammlung zur Geschichte der deutschen Sozialpolitik, Abt. I, 2. Bd., 1993, S. 482 Anm. 14. 
Abgrenzung des sozialversicherten Personenkreises eine Rolle spielt. ${ }^{78}$ Im Laufe der Zeit hat sich dazu ein zweiter Gesichtspunkt gesellt, nämlich die Bereitstellung und Vorhaltung von Gütern, also die Schaffung und Aufrechterhaltung der notwendigen Infrastruktur. Daraus folgt ein erstes Ziel sozialer Intervention: Einrichtungen sicherzustellen, die erschwingliche Leistungen in bestimmten Lebenslagen vorsehen, und den Zugang zu diesen zu sichern.

Zweitens ist für Sozialversicherungssysteme das Vorhandensein eines gewissen sozialen Ausgleichs innerhalb der Versichertengemeinschaft prägend. Das hat, unabhängig von der Anwendbarkeit des Wettbewerbsrechts, auch rechtliche Bedeutung im Hinblick auf die Kompetenzgrundlage für den Erlaß von Sozialversicherungsgesetzen. ${ }^{79}$ Zwar sind Risikoabsicherungssysteme, die auf Vorsorge beruhen, beitragsfinanziert; hier existiert eine (auch rechtlich relevante) Beziehung zwischen Leistung und Gegenleistung, ${ }^{80}$ aber grundsätzlich nicht im Sinne einer Äquivalenz, vor allem regelmäßig nicht im Sinne einer Risikobezogenheit. Vielmehr findet eine finanzielle Umverteilung zwischen den Versicherten statt, und zwar in klassischen Sozialversicherungssystemen sowohl aufgrund der unterschiedlichen Risikoanfälligkeit (also der Leistungsseite) als auch aufgrund der einkommensabhängigen Beitragsberechnung (d.h. auf der Beitragsseite).

Diese Effekte, als Ausdruck der Solidarität verstanden oder gar mit dieser gleichgesetzt, ${ }^{81}$ sind je nach Sicherungszweig unterschiedlich stark ausgeprägt. Sie werden offensichtlich grundsätzlich als gerecht empfunden, was sich theoretisch abstützen läßt. ${ }^{82}$ Grund dafür dürfte sein, daß die bestehenden Sicherungssysteme Risiken erfassen, die nicht nur alle treffen können, sondern deren Eintritt sowohl bis zu einem gewissen Grade auf Veranlagung beruht als auch die Lebensplanung tiefgreifend beeinträchtigen kann. ${ }^{83}$ Unterschiedlich hohe Beiträge lassen sich deshalb als angemessene Kosten für

78 Dazu vor allem Hase, Versicherungsprinzip und sozialer Ausgleich, 2000, S. 46 ff.; aus der jüngeren Rechtsprechung nur BVerfGE 113, 167 (zum Risikostrukturausgleich).

79 Vgl. Papier/Möller, Die Rolle des Solidarausgleichs in der gesetzlichen Unfallversicherung, NZS 1998, S. 353, 359.

80 Wenn auch die Einzelheiten umstritten sind; eine Beziehung zwischen Beiträgen und Leistungen verneinend BSG v. 29.1.2004, B 4 RA 29/03 R (www.bundessozialgericht.de), Rz. 83 ff.; a.A. $R u$ land, in: SRH, 3. Aufl. 2003, C 16 Rz. 29 ff. (S. 971); dazu wiederum krit. Schnapp, Buchbesprechung, NZS 2005, S. 586, 586. Zu der Diskussion ist zu sagen, daß es an einer rechtlichen Verbindung nicht schon deshalb fehlen muß, weil die Finanzierung in einem Umlageverfahren erfolgt; die Frage ist vielmehr, welches rechtliches Versprechen mit einer Beitragszahlung verbunden ist.

81 Vgl. zum Erfordernis der rechtlichen Strukturierung Kingreen, Das Sozialstaatsprinzip im europäischen Verfassungsverbund, 2003, S. 253 ff. (Solidarprinzip als Rechtsprinzip); Becker, Der Finanzausgleich in der gesetzlichen Unfallversicherung, 2004, S. $51 \mathrm{ff}$.

82 Vgl. auch Kersting, Gerechtigkeitsprobleme sozialstaatlicher Gesundheitsversorgung, in: ders. Politische Philosophie des Sozialstaats (Fußn. 66), S. 467, 489 f., der aufgrund gesellschaftsvertraglicher Überlegungen zu dem Schluß kommt, es bestünden überzeugende Gründe für eine „,solidargemeinschaftlich finanzierte Gesundheitsversorgung“.

83 Zum Versicherungscharakter und zur Ermutigung des „Einzelnen in die gesellschaftliche Zusammenarbeit zum gegenseitigen Vorteil“ (und gegen die Einstufung als „Konsum“) Ho- 
unterschiedliche Entwicklungschancen begreifen. Das heißt allerdings nicht, daß es nicht auch verteilungspolitische oder effizienztheoretische Gründe für eine andere Prämiengestaltung geben kann. ${ }^{84}$

Eine von der Ermöglichung des Zugangs und der Aufteilung der Kosten zu unterscheidende Rechtfertigung für staatliche Interventionen ist die Unterstützung derjenigen Personen ist, die aus materiellen Gründen nicht eigenständig vorsorge- und in diesem Sinne nicht marktfähig 85 sind. Diese Unterstützung kann je nach Anlage und Ausmaß des sozialen Ausgleichs in Vorsorgesysteme einbezogen werden, wird aber im übrigen vor allem durch Förderungs- und Hilfesysteme gewährt. Die staatliche Verantwortung kommt hier in der Finanzierung aus dem allgemeinen Haushalt zum Ausdruck, wobei sich die Leistungen nicht auf finanzielle Hilfen beschränken, sondern auch die Zurverfügungstellung von Einrichtungen und Diensten zum Gegenstand haben müssen.

\subsection{Funktionen des Wettbewerbs}

1.3.1. Als die neue soziale Frage ist von Eucken „die drückende Abhängigkeit ... (vom) Staat, die außerordentliche Gefährdung der menschlichen Freiheit, die Umwandlung des Menschen in das Teilstück einer großen Maschine“ genannt worden. ${ }^{86}$ Damit verbunden war ein Plädoyer zur Lenkung des Wirtschaftsprozesses durch die einzelnen Haushalte und Betriebe und zur gleichzeitigen staatlichen Gestaltung der Wirtschaftsordnung. ${ }^{87}$ Für diese Ordnung erscheint der Wettbewerb als prägend, ohne von der „freien Konkurrenz“ im Sinne der klassischen Nationalökonomie sprechen zu müssen. 88

Auch wenn mit weniger starken Bilder argumentiert wird, bleibt die Erkenntnis wichtig, daß Wettbewerb nicht mehr nur ein Mechanismus der Preisbildung darstellt, sondern verschiedene Funktionen erfüllt und auf diese Weise Grundlage der sozialen Marktwirtschaft 89 ist. 90 Diese Funktionen sind namentlich Allokation, Innovation und

mann/Suchanek, Ökonomik, 2. Aufl. 2005, S. 141 f. Krit. aber zu dem Versuch, Sozialversicherung alleine aufgrund von Effizienzüberlegungen als gerecht darzustellen, Schefczyk/Piddat, Effizienz und Gerechtigkeit, in: Kersting, Politische Philosophie des Sozialstaats (Fußn. 66), S. 428, $460 \mathrm{ff}$.

84 Dementsprechend wird eine Änderung der Beitragsgestaltung sowohl auf Gründe der gerechteren Verteilung der Beitragslast (i.e. alle Steuerzahler) wie auch auf die Ermöglichung einer wettbewerblichen Gestaltung oder die Entlastung der Arbeitskosten gestützt; vgl. etwa Gutachten des Wissenschaftlichen Beirats beim Bundesministerium der Finanzen, Nachhaltige Finanzierung der Renten- und Krankenversicherung, 2004, S. $23 \mathrm{ff}$.

85 Vgl. dazu auch unten, 3. b) Handlungsoptionen.

86 Eucken, Die soziale Frage, in: Festgabe für A. Weber, 1948, S. 113, 119.

87 A.a.O., S. $129 \mathrm{f}$.

88 Krit. zur Folgerung der Zulassung eines ,laisser faire“ vor dem eigenen theoretischen Hintergrund Schumpeter, Das Wesen und der Hauptinhalt der Theoretischen Nationalökonomie, 1908 (3. Aufl. 1998), S. 192 f.

89 Zur Begründung durch die Freiburger und Kölner Schule und derem Inhalt die Beiträge in Nörr/Starbatty (Hrsg.), Soll und Haben, 50 Jahre Soziale Marktwirtschaft, 1999. Zu den berühmten 
Freiheitsschaffung, ${ }^{91}$ wobei der Frage, inwieweit die Wettbewerbsfreiheit einen Wert an sich darstellt, ${ }^{92}$ nicht nachgegangen werden muß. Zur Funktionserfüllung bedarf es der Beachtung bestimmter Voraussetzungen. Diese beziehen sich wiederum auf Marktstrukturen, Marktverhalten und Marktergebnisse. ${ }^{93}$

1.3.2. Das geltende Wettbewerbsrecht ist sowohl in Deutschland als auch in der Europäischen Gemeinschaft der Sicherung dieser Voraussetzungen, wenn auch in unterschiedlicher Weise, gewidmet. ${ }^{94} \mathrm{Ihm}$ geht es um die Offenhaltung des Zugangs zum Markt und um die Verhinderung von Machtmißbrauch, damit in erster Linie um die Sicherung fairer Marktverhältnisse - allerdings ohne auf eine Ergebniskontrolle zu verzichten. Im Gegenteil rücken neuere wettbewerbspolitische Ansätze Ergebnisse im Sinne der Sicherung eines Marktes ohne Machtkonzentration in den Vordergrund. ${ }^{95}$ Gerade die Erwartung, daß ein unbeschränkter Wettbewerb unter bestimmten Voraussetzungen zu ungünstigen Ergebnissen führen kann, dient auch zur Rechtfertigung von Wettbewerbsbeschränkungen. ${ }^{96}$ Werden dementsprechend marktbeherrschende Stellungen hingenommen, scheidet eine Preisbildung über den Wettbewerb aus, und es bleibt ersatzweise die Möglichkeit der Preisregulierung, um Verbraucher zu schützen.

Die Frage, ob und wie eine Ergebnissicherung betrieben werden kann, ist im übrigen ebenso grundlegend wie schwierig. Offensichtlich schützt die geltende Rechtsordnung trotz ihrer freiheitlichen Ausrichtung nicht jegliche Form des Wettbewerbs und begnügt sich bei den als notwendig erachteten Regulierungen auch nicht mit Verhaltensanforderungen.

„dritten Wegen“ Schüller, Soziale Marktwirtschaft und Dritte Wege, ORDO 51 (2000), S. 169, 185 ff.

$90 \mathrm{Zu}$ deren Bedeutung für die Wirtschaftsverfassung der EU jetzt auch der (zwar zunächst gescheiterte, aber für die weitere Entwicklung wohl dennoch richtungsweisende) Verfassungsvertrag (Abl. C310 v. 16.12.2004 ), Art. I - 3 „Die Ziele der Union“, Abs. 3.

91 Vgl. Herdzina, Wettbewerbspolitik, 5. Aufl. 1999, S. 11 ff.; Knieps, Wettbewerbsökonomie. Regulierungstheorie, Industrieökonomie, Wettbewerbspolitik, 2001, S. 4 ff.

92 Dazu nur Vanberg, Konstitutionenökonomische Überlegungen zum Konzept der Wettbewerbsfreiheit, ORDO 52 (2001), S. $37 \mathrm{ff}$.

93 Zusammenfassend jetzt Musil, Wettbewerb in der staatlichen Verwaltung, 2005, S. 19 f.

94 Näher Mestmäcker/Schweitzer, Europäisches Wettbewerbsrecht, 2. Aufl. 2004,§ 2, Rdnr. 84 ff.

95 Mit Art.2 Abs.2 und 3 der FKVO v. 20.1.2004 (ABl. 2004 Nr.L 24/1) tritt nun das Kriterium der Wettbewerbsbehinderung anstelle dem der Marktbeherrschung in den Vordergrund. Vgl. dazu Böge, Reform der Europäischen Fusionskontrolle, WuW 2004, S. 138, 143 ff.

96 Mestmäcker/Schweitzer, Europäisches Wettbewerbsrecht, 2. Aufl. 2004, § 2, Rdnr. 96. 


\section{Wahlmöglichkeiten und die Anwendung des Wettbewerbs- und Sozialrechts}

\subsection{Handlungsfreiheiten}

2.1.1. Wettbewerb setzt Handlungsfreiheiten voraus. Er ist deshalb beschrieben worden als „ein komplexes System von Marktprozessen, das aufgrund der Freiheit, an Marktprozessen teilzunehmen und innerhalb dieser nach eigenem Plan tätig sein zu können, herauswächst."97 Hier besteht ein grundlegender Unterschied zur Ordnung der Sozialleistungssysteme, die vielfach auf hoheitliche Festlegungen setzt. Das betrifft die Frage, wer Versicherungsschutz erhält, aber auch, welche Leistungen ihm gewährt werden und welche Preise dafür gezahlt werden sollen. Hintergrund dafür ist wiederum die Annahme des Marktversagens bzw. der Marktineffizienz, ${ }^{98}$ die vor allem auf den in verschiedener Hinsicht bestehenden Informationsdefiziten beruht. 99 Diese beziehen sich schon auf die Entscheidung, eine Versicherung zu nehmen, ebenso auf die Qualität und den Preis der Leistungen. Sie sind im übrigen für alle Versicherungsmärkte relevant, ${ }^{100}$ lassen sich aber für Sozialversicherungssysteme zumindest zum Teil auch auf die Besonderheit des zu gewährenden Gutes stützen. ${ }^{101}$

\subsubsection{Allerdings müssen die angedeuteten Erfordernisse des Versicherungszwangs} und der Festlegung des Versicherungsinhalts nicht zwangsläufig jegliche Handlungsspielräume ausschließen. ${ }^{102}$ Hier sei zunächst nur allgemein darauf hingewiesen, daß die Gründe, die für eine Beachtung des „Sozialen“ sprechen, bei der Einschaltung von Privaten zu Beschränkungen der Privatautonomie und damit der Spielräume für den Wettbewerb führen müssen. ${ }^{103}$ In welchem Umfang das wünschenswert ist, ist nicht nur eine Frage der Effizienz, sondern auch der Ordnungspolitik und der jeweiligen verfassungsrechtlichen Vorgaben. Ohne darauf näher einzugehen: Eine Einschränkung von

97 Hoppmann, Fusionskontrolle, 1972, S. 9.

98 Krit. dazu jedenfalls im Hinblick auf die gegenwärtige Ausgestaltung der sozialen Sicherungssysteme Berthold, Marktversagen, staatliche Intervention und Organisationsformen sozialer Sicherung, in: Rolf/Spahn/Wagner (Hrsg.), Sozialvertrag und Sicherung, 1988, S. 339 ff.

99 Dazu (für das Gesundheitswesen) Breyer/Zweifel/Kifmann, Gesundheitsökonomik, 5. Aufl. 2004, S. 179 ff.; zusammenfassend Spiecker gen. Döhmann, Zur Wettbewerbsfähigkeit der Gesundheitsgüter, in: Schmehl/Wallrabenstein (Hrsg.), Steuerungsinstrumente im Recht des Gesundheitswesens, Bd. 1: Wettbewerb, 2005, S. 1, 13 ff.

100 Vgl. nur Barr, The Economics of the Welfare State, 3. Aufl. 1998, S. 121.

101 Wiederum für Gesundheitsleistungen Kersting, Gerechtigkeitsprobleme sozialstaatlicher Gesundheitsversorgung, in: ders., Politische Philosophie des Sozialstaats (Fußn. 66), S. 467, 475 ff.; Spiecker gen. Döhmann, in: Steuerungsinstrumente (Fußn. 99), S. 1, 19.

102 Vgl. unten IV.2.

103 Das zeigt die Diskussion um managed care in den USA; dazu Rich, The Two Faces Of Managed Care Regulation and Policymaking, in Stanford Law \& Policy Review 2005 (volume 16), S. 233 ff., vgl. allgemein Freeman/France, Managed competition, working paper 2000 (http://www.pol.ed.ac.uk/freeman/workingpapers/managedcompetition.pdf) 
Freiheitsrechten darf jedenfalls nicht ohne weiteres auf die prinzipielle Zulässigkeit einer staatlichen Aufgabenübernahme gestützt werden, wenn der Staat die Erledigung der Aufgabe Privaten überläßt. Umgekehrt sind nicht alle Besonderheiten der Sozialversicherung durch private Versicherungsträger erfüllbar. ${ }^{104}$

Bei alledem ist zu bedenken, daß auch innerhalb einzelner Leistungssysteme Funktionen aufgespalten und dementsprechend unterschiedlich große Handlungsspielräume geschaffen werden können. ${ }^{105}$ Ferner kann es genügen, die aus dem Sozialen im vorstehenden Sinn abgeleiteten Anforderungen in allgemeiner Weise durch gesetzliche Vorgaben zu sichern. So können etwa Qualitätsstandards außerhalb des Versicherungssystems in allgemeiner Weise vorgegeben werden. Das ist ein Ansatz, der auch der Rechtsprechung des EuGH zur Kostenerstattung für grenzüberschreitende Behandlungsleistungen zugrundeliegt. 106

\subsection{Tatsächliche Handlungsmöglichkeiten}

Natürlich dürfen nicht nur die rechtlichen, sondern es müssen die tatsächlich bestehenden Wahlmöglichkeiten betrachtet werden. Das gilt zunächst ganz allgemein deshalb, weil ein Wettbewerb von den zur Entscheidung Aufgerufenen auch Entscheidungsfähigkeit fordert. Marktfähigkeit kann nicht nur wegen fehlender materieller Mittel ausgeschlossen sein, sondern auch wegen fehlender Erfahrungen mit eigenverantwortlichem Handeln oder fehlender Entschlußfähigkeit, 107 und gerade diejenigen, die Sozialleistungen in Anspruch nehmen (müssen), sind aus verschiedenen Gründen in ihren Entscheidungsmöglichkeiten beschränkt (oder neigen zu Entscheidungen, die die Zwecksetzung eines Leistungssystems gefährden ${ }^{108}$ ). So zutreffend diese Beobachtung ist, schließt sie doch die Eröffnung von Handlungsoptionen und damit auch von Wettbewerbsspielräumen nicht aus. Sie spricht aber eindeutig für eine zeilgerichtete Regulierung der Wettbewerbsbedingungen.

Tatsächliche Handlungsmöglichkeiten bestehen aber insbesondere und ganz praktisch gesehen nur dann, wenn zwischen mehreren Anbietern einer Leistung gewählt werden kann. Gerade einige der unter der Fahne des Wettbewerbs eingeführten Instrumente, nämlich integrierte Versorgung bzw. managed care und Einzelverträge, führen und das ist der Grund, warum verstärkt das Vergaberecht zur Anwendung gelangt - zu

104 Wie eine Finanzierung im Umlageverfahren; nicht zuletzt daraus erklären sich gerade die Möglichkeiten der gegenseitigen Ergänzung und des Systemwettbewerbs.

105 Näher zur Unterscheidung von Angebots- und Nachfrageseite unten, III.

106 Bezogen auf die Anforderungen an die Ausbildung der Ärzte oder die Ausstattung von Krankenhäusern, vgl. dazu nur Becker/Walser, Stationäre und ambulante Krankenhausleistungen im grenzüberschreitenden Dienstleistungsverkehr - von Entgrenzung und Grenzen in der EU, NZS 2005, S. 449 ff.

107 Näher Nullmeier, Vermarktlichung des Sozialstaats, WSI Mitt. 9/2004, S. 495, 497 f.

108 Das gilt für steuerfinanzierte Leistungen ebenso wie für Zwangsversicherungen, wenn dort eine Spreizung der Prämien bzw. Beiträge je nach Inanspruchnahme von Gütern nicht vorgesehen ist. 
einer Verengung von Optionen, jedenfalls aus Sicht der Versicherten bzw. Patienten. ${ }^{109}$ Das ist nur dann hinnehmbar, wenn, dem oben ausführlich dargestellten Leistungsdreick folgend, Wahlmöglichkeiten im Verhältnis zu den Versicherern offenstehen.

\subsection{Verläßlichkeit}

Ein grundlegendes Problem für das Verhältnis von Sozialem und Wettbewerb stellt die Verläßlichkeit dar. Für das Soziale ist entscheidend, daß in bestimmten Bedarfssituationen Leistungen erbracht werden, deren Höhe - innerhalb normativer Grenzen - einer politischen Entscheidung folgt. Wettbewerb als Entdeckungsverfahren ist ein Verfahren zur Entdeckung von Handlungsoptionen, die ohne sein Bestehen entweder unbekannt bleiben oder doch zumindest nicht genutzt werden würden. ${ }^{110}$ Es wäre nicht notwendig, wenn seine Ergebnisse vorhersagbar wären. ${ }^{111}$ In diesem Sinne ist mit Wettbewerb die Übernahme eines unternehmerischen Risikos verbunden, ${ }^{112}$ was wiederum einer sozialen Funktion widerspricht.

So unterschiedlich die Ansätze sind, sie führen nicht zwangsläufig zu einem gegenseitigen Ausschluß von Wettbewerbs- und Sozialrecht. Vielmehr folgt aus ihnen zunächst nur, daß Sozialrecht seine eigene Ergebniskontrolle an die Stelle der wettbewerbsrechtlichen stellen muß - oder konkreter, der intervenierende Staat die gewünschten Ergebnisse vorgeben muß. Dennoch ist es möglich, deren Sicherung, insbesondere jene vor Insolvenz, als Rahmenbedingung festzuschreiben und eventuell gesonderten Einrichtungen zu überlassen. ${ }^{113} \mathrm{Da}$ dies mit Kosten verbunden sein wird, ist bei der Wahl der institutionellen Ausgestaltung zu bedenken. Ähnliche Überlegungen gelten für die Bereitstellung der erforderlichen Infrastruktur, insbesondere für die Krankenbehandlung und Pflege. Hier sind -auch wegen des Erfordernisses eine flächendeckenden Versorgung - eine staatliche Planung und eine staatliche Bereitstellungsverantwortung nötig. Angesichts vielfacher Unsicherheiten besteht für die Wahrnehmung dieser staatlichen Aufgabe ein Gestaltungsspielraum. Dessen Ausfüllung muß Effizienz gewährleisten, ohne das Sicherungsziel zu vernachlässigen.

109 Vgl. unten, IV.2.2.

110 Vgl. v. Hayek, Der Wettbewerb als Entdeckungsverfahren, 1968, S. 3.

111 Vgl. v. Hayek, Recht, Gesetz und Freiheit, 2003, S. 374 f.

112 v. Hayek erweitert dieses Entdeckungsverfahren Wettbewerb daneben um den Gedanken, daß nicht nur jedem, der die Gelegenheit hat, besondere Umstände zu nützen, die Möglichkeit eröffnet wird, dies gewinnbringend zu tun, sondern auch jedem anderen Beteiligten die Information vermittelt wird, daß es eine solche Gelegenheit gibt, so in: Recht, Gesetz und Freiheit (Fußn. 111), S. 268.

113 So wie dies in der deutschen betrieblichen Altersversorgung durch den Pensionssicherungsverein geschieht, ebenso auf privatrechtlicher Grundlage in der privaten Lebensversicherung. Vgl. auch Becker, Generalbericht, in: Schlachter/Becker/Igl (Hrsg.), Funktion und rechtliche Ausgestaltung zusätzlicher Alterssicherung, 2005, S. 107, 138 ff. 


\section{Wahlmöglichkeiten im Leistungsdreieck- zur Länderauswahl}

\section{Wahlmöglichkeiten trotz Anbietermonopols}

Je vielfältiger die Wahlmöglichkeiten, desto mehr Möglichkeiten bestehen, Wettbewerb als Steuerungsinstrument einzusetzen. Allerdings wäre es nicht richtig umgekehrt anzunehmen, daß in Ländern mit einem einzigen Sozialleistungsträger oder mit mehreren, aber wegen einer gesetzlich fixierten Zuständigkeit für jeweils andere Gruppen von Versicherten nebeneinander stehenden Sozialleistungsträgern der Wettbewerb von vornherein gar keine Rolle spielen könnte. Er kann vielmehr auch hier stattfinden, allerdings in enger umgrenztem Rahmen. Dabei spielt die Organisationsform der Gesundheitsversorgung keine entscheidende Rolle. Es kommt also nicht darauf an, ob das Gesundheitswesen durch einen nationalen Gesundheitsdienstes (wie in vielen europäischen Ländern, nämlich neben dem Vereinigten Königreich auch in den skandinavischen und südeuropäischen Staaten) oder durch eine Sozialversicherung (wie etwa in Frankreich, Belgien oder Österreich) durchgeführt wird.

\subsection{Bezogen auf das Versicherungsverhältnis}

Soweit das Angebot von Versicherungsleistungen betroffen ist, also im Rechtsverhältnis zwischen Versichertem und Leistungsträger, kann es einen Wettbewerb dort geben, wo ein Monopol der Sozialleistungsträger nicht besteht. Das ist in zwei Varianten möglich, nämlich sachlich, bezogen auf den Umfang der Absicherung, und personell, bezogen auf die gesicherten Personengruppen. Gewähren Sozialleistungsträger nur ein Basisniveau sozialer Leistungen, so bleibt erstens Raum für einen Markt der ergänzenden Leistungen. Ist das der Fall, werden dort private Anbieter miteinander konkurrieren, wobei zugleich der Bedarf an staatlicher Regulierung wegen der gesicherten Basisversorgung abgesenkt sein wird. Ob auch Sozialversicherungsträgern Zugang zu diesem Markt haben sollen oder dürfen, ist ordnungspolitisch und rechtlich fraglich. 114

Zweitens kann ein Wettbewerbsfeld entstehen, wenn der Versicherungszwang nicht umfassend angelegt ist. Auch auf diesem können nur Private miteinander konkurrieren oder Private mit Sozialversicherungsträgern, wenn diesen die Möglichkeit einer freiwil-

114 Vgl. dazu Becker, Verfassungs- und gemeinschaftsrechtliche Bewertung einer Erweiterung der Aufgaben von Sozialversicherungsträgern, in: N. Klusen (Hrsg.), Zuwahlleistungen in der gesetzlichen Krankenversicherung, 2003, S. 57 ff.; Axer, Soziale Sicherheit vor neuen Grenzziehungen zwischen öffentlichem und privaten Recht, in: Soziale Sicherheit durch öffentliches und Privatrecht, SDSRV 51 (2003), S. 111, 123 ff. 
ligen Versicherung eingeräumt wird. ${ }^{115}$ Im erstgenannten Fall sind keine sozialrechtlichen Besonderheiten notwendig. Regulierungen enthält aber das Versicherungsrecht, das zunehmend nicht nur objektiv der Ordnung des Wirtschaftslebens, sondern zugleich dem Verbraucherschutz dient. Im letztgenannten konkurrieren sozialrechtliche und privatrechtliche Gestaltung unmittelbar miteinander, was zwar die Unterschiede als solche nicht in Frage stellt, ${ }^{116}$ aber einer sozialrechtlichen Ausgestaltung bedarf.

\subsection{Bezogen auf das Leistungserbringungsverhältnis}

Weil das Leistungserbringungsverhältnis mehrpolig ist, muß ein Wettbewerb nicht an dem Sozialleistungsverhältnis zwischen Ver- bzw. Gesicherten einerseits und Leistungsträger andererseits ansetzen. Er kann stattdessen lediglich das Verhältnis zwischen Leistungsträgern und Leistungserbringern betreffen. Das setzt voraus, daß die Leistungserbringer nicht in einem Arbeitsverhältnis zum Leistungsträger oder zu einem dem Träger rechtlich zurechenbaren Einrichtung stehen.

Ein solcher Wettbewerb bezieht sich, unter den genannten institutionellen Voraussetzungen, auf die Nachfrage der Leistungsträger nach Gesundheitsleistungen. Im englischen National Health Service ist ein entsprechender Ansatz verfolgt worden. 1990 wurde dort mit dem National Health Service and Community Care Act $1990^{117}$ ein sog. „internal market“ eingeführt. 118 Grundlage war die Trennung des Einkaufs von Leistungen von der eigentlichen Leistungserbringung. Die nicht notärztlichen Leistungen waren durch General Practitioners - GPs - als fundholders einzukaufen, falls sich diese für die fundholding option entschieden, ${ }^{119}$ und im übrigen durch örtliche health authorities. Die Leistungserbringung oblag insbesondere den neu geschaffenen NHS Trusts ${ }^{120}$.

Diese „Märkte“ sollten unter New Labour wieder abgeschafft werden. Der Hintergrund hierfür war zum einen ideologisch, zum anderen hatte das fundholding den bürokratischen Aufwand und damit die Transaktionskosten erheblich erhöht ${ }^{121}$ sowie zu

115 Wie im deutschen Krankenversicherungsrecht angesichts der oberen Versicherungspflichtgrenze, dazu nur Becker, German Health and Long-Term Care Insurance - Legal Aspects, in: The Role of Private Actors in Social Security, German-Japanese Social Law Symposium, MPISoc Working Papers 1/2005, S. 3 ff. (http://www.mpisoc.mpg.de/pub/downloads/WP001.pdf).

116 Dazu jetzt auch Mühlenbruch, System-,,wettbewerb“ zwischen GKV und PKV, in: Schmehl/Wallrabenstein (Hrsg.), Steuerungsinstrumente im Recht des Gesundheitswesens, Bd. 1: Wettbewerb, 2005, S. $37 \mathrm{ff}$.

1171990 chapter 19.

118 Siehe Department of Health, Working for Patients, 1989, S. 3 ff..

119 Die Details hierzu regelten die National Health Service (Fund-holding Practices) Regulations 1996 (SI 1996 No. 706). Ausführlich zum GP fundholding etwa Goodwin, GP fundholding, in: Le Grand/Mays/Mulligan (eds.), Learning from the NHS Internal Market, 1998, S. 42 ff.

120 Nunmehr geregelt in den sections 25 ff. des National Health Service Act 2006 (2006 chapter 41).

121 Goodwin, GP fundholding, in: Le Grand/Mays/Mulligan, Learning from the NHS Internal Market, 1998, S. 52 f. 
lokalen Ungleichheiten beim Zugang zu Leistungen geführt. ${ }^{122}$ Die im Jahre 1997 begonnene Politik richtete sich allerdings eher gegen den Preiswettbewerbs als gegen ein Ende der Trennung zwischen Einkauf und Erbringung von Leistungen. Dem Preiswettbewerb wurde durch die Einführung nationaler Standardtarife (Payment by Results) der Boden entzogen. Und während auch das GP fundholding abgeschafft wurde, obwohl bis $1997 / 199857$ \% der GPs dafür optiert hatten, ${ }^{123}$ blieb die commissioning-Funktion auf Seiten der Health Authorities und mit ihr der purchaser-provider-split erhalten.

Im Hinblick auf die weiterhin bestehende Trennung zwischen Leistungsbezug und Leistungsangebot hätte von einem Wettbewerb um Qualität gesprochen werden können. In der Rhetorik der Regierung unter New Labour stand jedoch nicht mehr länger der Markt im Vordergrund. ${ }^{124}$ Vielmehr sollte auch im NHS ein „Third Way" eingeschlagen werden, gedacht als Partnerschaft mit dem privaten Sektor und gerichtet auf die gemeinsam anzustrebende Verbesserung der Qualität und Einräumung von Wahlmöglichkeiten. ${ }^{125}$ Der Sache nach waren damit Marktelemente im NHS nicht abgeschafft worden. Ganz folgerichtig wurde später auch wieder von cooperation and competition als den Mechanismen zur Steigerung der service quality gesprochen. ${ }^{126}$

Die zentralen fundholder des englischen Gesundheitssystems sind die derzeit ca. 150 Primary Care Trusts ${ }^{127}$, die sich seit 2002 aus den ehemaligen Health Authorities entwickelt haben. ${ }^{128}$ Sie sind für ca. $80 \%$ des NHS Budgets zuständig und bieten eine Reihe von Primary Care Services direkt an. Dieses Direktangebot, zu dessen Erbringung es bislang keine purchaser-provider-splits innerhalb der Primary Care Trusts gibt, soll künftig zugunsten des Marktes zurückgefahren, wenn auch nicht vollständig abgeschafft werden. ${ }^{129}$ Die Primary Care Trusts kaufen auch Leistungen bei NHS Trusts (wie den NHS Hospital Trusts, den NHS Mental Health Service Trusts oder den NHS Ambulance Services Trusts bzw. den sog. Foundation Trusts, einer neuen Organisationsform staatlicher Leistungserbringer, die über eine größere Unabhängigkeit gegenüber Weisungen

122 S. Davies, A Tangled Web? Accountability and the Commissioning Role in the 'New' NHS, (2007) 18 King's Law Journal, S. 387, 389; Curry/Thorlby, Practice-based Commissioning, 2007, S. 2.

123 Kay, The abolition of the GP fundholding scheme: a lesson in evidence-based policy making, British Journal of General Practice 2002 (52), S. 141.

124 Vgl. nur Department of Health, The New NHS: Modern, Dependable, 1997, S. 16: "How we are replacing the Internal Market with Integrated Care".

125 S. etwa Department of Health, The New NHS: Modern, Dependable, 1997, S. 24; Department of Health, Creating a Patient-led NHS, 2005, S. 13 ff.

126 Vgl. nur Department of Health, Principles and rules for Cooperation and Competition, 2007.

127 Nunmehr sections 18 ff. des National Health Service Act 2006 (2006 chapter 41).

128 Dazu Department of Health, The New NHS: Modern, Dependable, 1997, S. 32 ff..

129 Department of Health, Health Reform in England: Update and Commissioning Framework, 2006, S. 25 ff.; dass., Commissioning a Patient-Led NHS, 2005, S. 4.; vgl. auch Davies, A Tangled Web? Accountability and the Commissioning Role in the 'New' NHS, (2007) 18 King's Law Journal, S. $387,393 \mathrm{f}$. 
des Secretary of State verfügen ${ }^{130}$ ) sowie bei Anbietern des privaten Sektors (wie den Independent Sector Treatment Centres ${ }^{131}$ ) ein. Sie haben die Vorgabe, bis Ende 2008 $15 \%$ der Primary Care Leistungen (d.h. der ärztlichen Grundversorgung, die auch stationär Leistungen umfaßt, aber von der Facharztversorgung abzugrenzen ist) vom privaten Sektor zu beziehen. ${ }^{132}$ Ferner schließen die Primary Care Trusts Verträge mit selbständigen $G P s$ und Zahnärzten ${ }^{133}$ ab und bezahlen diese für ihre Leistungen.

Seit 2005 wird zudem versucht, die GPs wieder stärker als Entscheidungsträger bzgl. der Frage, welche Leistungen der Patient erhalten soll und für welche Leistungen Gelder aufgewendet werden sollen, einzubinden. Hierdurch soll die Anzahl teurer Krankenhauseinweisungen verringert und ein stärkerer Fokus auf örtliche ambulante Krankenleistungen (,care closer to home“ Policy) gelegt werden. Um diese Ziele zu erreichen, wurde das sog. Practice-based Commissioning $(\mathrm{PbC})$ eingeführt. ${ }^{134} \mathrm{PbC}$ soll zugleich einen wesentlichen Baustein zur Umsetzung der patient choice Policy darstellen, indem den Patienten von ihrem GP eine Reihe verschiedener Leistungserbringer aufgezeigt werden sollen, von denen sie Leistungen beziehen können. ${ }^{135}$

Im Rahmen des $P b C$ bekommen die GPs von den Primary Care Trusts ein sog. ,indikatives" Budget (indicative budget) zugewiesen und erhalten Informationen über die Menge und die Kosten der Leistungen, die ihre Patienten derzeit vom NHS beziehen, sowie englandweite Vergleichsdaten. Mit den zugeteilten Geldern sollen die GPs entweder selbst (bislang nicht von ihnen selbst angebotene und nicht von den normalen $G P$ Verträgen umfaßte) Leistungen erbringen oder Leistungen der Primary und Secondary Health Care für ihre Patienten extern beziehen. ${ }^{136}$ Die Preise für die Leistungen sind anders als noch im Rahmen des GP fundholding - durch die Payment by Results Tarife festgelegt. ${ }^{137}$ Die Aushandlung und Abwicklung der Verträge mit externen Anbietern

130 Sections 30 ff. des National Health Service Act 2006 (2006 chapter 41); hierzu Davies, Foundation Hospitals: A New Approach to Autonomy in the Delivery of Public Services?, Public Law 2004, S. $808 \mathrm{ff}$.

131 Näher zu den unabhängigen Behandlungszentren Thomsen/Smith, Mit privatem Geld aus der Krise, Deutsches Ärzteblatt 2008 (105). S. 1249 f.

132 Department of Health, The NHS Improvement Plan, Putting People at the Heart of Public Services, 2004, S. 52.

133 Die für die Zahnärzte 2006 neu gefaßten Government Contracts schränkten die zahnärztlichen NHS Leistungen erheblich ein, so daß ca. 10\% der Zahnärzte diesen Vertrag nicht mehr abgeschlossen haben. Viele Zahnärzte behandeln nur noch Privatpatienten (vgl. http://news.bbc.co.uk/1/hi/health/5278048.stm).

134 S. Department of Health, Practice-Based Commissioning: Practical Implementation, 2006.

135 Curry/Thorlby, Practice-based Commissioning, 2007, S. 2.

136 Dazu etwa Davies, A Tangled Web? Accountability and the Commissioning Role in the 'New' NHS, (2007) 18 King's Law Journal, S. 387, 398 ff.; Curry/Thorlby, Practice-based Commissioning, 2007.

137 Vgl. Department of Health, National Tariff 2007-08, 2006 (http://www.dh.gov.uk/en/Publicationsandstatistics/Publications/PublicationsPolicyAndGuidance/DH_4140197?IdcService=GET_FILE\& $\mathrm{dID}=12687 \&$ Rendition=Web); s. auch. Davies, A Tangled We- ? Accountability and the Commissioning Role in the 'New' NHS, (2007) 18 King's Law Journal, S. 387, 390. 
wird weiterhin von den Primary Care Trusts und nicht von den GPs betrieben. ${ }^{138}$ Die von den GPS intendierten Umstrukturierungen der Diensterbringung müssen von den Primary Care Trusts zudem jeweils erst gebilligt werden. ${ }^{139}$ Der Hauptanreiz für die $G P s$, freiwillig für $P b C$ zu optieren, besteht darin, daß sie bis zu $70 \%$ der Einsparungen für sich selbst behalten dürften, der restliche Teil geht an die Primary Care Trusts. ${ }^{140}$ Zudem wurden bis Ende 2007 sog. Direct Enhanced Service - Zahlungen an GPs überwiesen, wenn sie ,sich für $P b C$ entschieden. ${ }^{141}$ Ein weiterer Anreiz für die GPs besteht darin, daß sie ihre eigenen Leistungen ausweiten können und zu den nationalen Tarifen gewissermaßen an sich selbst verkaufen können. Diese Gelder treten dann zu den weiterhin bestehenden, außerhalb der $P b C$ budgets unverändert laufenden Verträgen für die herkömmlichen GP Leistungen (General Medical Services und Personal Medical Services) hinzu. ${ }^{142}$

Anders als noch im Rahmen des fundholding sind die Budgets aber nicht real, sonders sie verbleiben als ,indikative“ Budgets ${ }^{143}$ zur Verwaltung bei den Primary Care Trusts, die auch weiterhin für diese Gelder verantwortlich sind. Die Berechnung der Budgets wird sukzessive von einem am bisherigen Aufwand orientierten Berechnungsansatz auf alters- und morbiditätsbasierte, fair shares" umgestellt. ${ }^{144}$ Die GPs müssen sich bemühen, innerhalb ihres Budgets zu bleiben. Nicht ganz klar ist jedoch, was in den Fällen geschieht, in denen Budgets überschritten werden. Ausgleichszahlungen seitens der GPS sind nicht vorgesehen, die GPs dürften in den Folgejahren aber einer erhöhten Überwachung durch die Primary Care Trusts ausgesetzt sein, die für einen ausgeglichenen Haushalt letztverantwortlich bleiben. ${ }^{145}$ Hintergrund des weitgehenden Schweigens der Policy Dokumente hierzu dürfte sein, daß das $P b C$ den GPs als attraktive Alternative vorgestellt werden sollte und deshalb die neuen Möglichkeiten und Freiheiten in den Vordergrund gestellt wurden ${ }^{146}$ und auf die Rationalisierungsmomente demgegenüber nicht explizit eingegangen wurde. Allerdings wird den Primary Care Trusts ein Fonds nahegelegt, von dem außergewöhnlich teure Behandlungen aufgefangen werden sollen, damit diese nicht auf das GP Budget durchschlagen. ${ }^{147}$ Die Imple-

138 Department of Health, Practice-Based Commissioning: Achieving Universal Coverage, 2006, S. 11,

139 Vgl. Department of Health, Practice-Based Commissioning: Practical Implementation, 2006, Absatznr. 2.9.

140 S. Department of Health, Practice-Based Commissioning: Achieving Universal Coverage, 2006, S. 10; dass., Practice-Based Commissioning: Practical Implementation, 2006, Absatznr. $3.21 \mathrm{ff}$.

141 S. Curry/Thorlby, Practice-based Commissioning, 2007, S. 3 f.

142 Department of Health, Practice-Based Commissioning: Achieving Universal Coverage, 2006, S. 8.

143 Näher hierzu Curry/Thorlby, Practice-based Commissioning, 2007, S. 4.

144 Vgl. etwa Department of Health, Supporting practice based commissioning in 2007/08 by determining weighted capitation shares at practice level, 2007.

145 Department of Health, Practice-Based Commissioning: Achieving Universal Coverage, 2006, S. 13.

146 So auch Davies, A Tangled Web? Accountability and the Commissioning Role in the 'New' NHS, (2007) 18 King's Law Journal, S. 387, 400.

147 Department of Health, Practice-Based Commissioning: Practical Implementation, 2006, Absatznr. $3.27 \mathrm{ff}$. 
mentation der $P b C$ steht erst am Anfang, aussagekräftige empirische Daten liegen dazu noch nicht vor.

\section{Wettbewerb auf Angebotsseite}

Im Vergleich $\mathrm{zu}$ dem vorstehend beschriebenen Konzept der internal markets in England ergeben sich zusätzliche Wahlmöglichkeiten, wenn auf der Seite der Verscherungsträger keine gesetzlich festgelegten Zuständigkeiten vorgesehen sind, sondern die Versicherten den Träger wählen können. Ein entsprechender Wettbewerb bezieht sich auf das Angebot von Versicherungen. Er ist - oder sollte es jedenfalls sein - die Regel, wenn der Schutz durch eine Privatversicherung bereitgestellt wird. In diesen Fällen wird das Versicherungsverhältnis durch privatrechtlichen Vertrag begründet, ${ }^{148}$ und auf einem funktionierenden Markt besteht eine Auswahl zwischen verschiedenen Anbietern. Faktoren für die Wahlentscheidung der Versicherten sind Umfang, Preis und Qualität der Leistung. Dafür kann - tatsächlich oder auch nur in der Vorstellung der Versicherten - zudem die Frage eine Rolle spielen, durch wen die Leistungen erbracht werden. Versicherer können versuchen, mit ausgewählten Leistungserbringern Absprachen zu treffen und auf diese Weise Qualität und bzw. oder den Preis der Leistungen zu beeinflussen. In diesen Fällen wird der zunächst auf das Versicherungsverhältnis bezogene Wettbewerb mit einem Wettbewerb auf der Leistungserbringungsseite verknüpft.

\subsection{Wahlmöglichkeiten auf Angebotsseite}

Die angesprochenen Wahlmöglichkeiten auf Angebotsseite können in sehr unterschiedlich angelegten Systemen vorgesehen werden. Eine vergleichende Bestandsaufnahme läßt drei verschiedene Ausgestaltungen erkennen.

2.1.1. Die erste findet sich in Deutschland. Hier besteht für weite Bereiche der Gesundheitsversorgung, nämlich soweit die Pflichtversicherung reicht, ein Versicherungsmonopol. Jedoch werden verschiedene Träger eingesetzt, um die gesetzliche Krankenversicherung durchzuführen. Diese Träger versichern seit 1996 nicht mehr einen durch Gesetz zugewiesenen Kreis von Personen. Vielmehr können die Versicherten zwischen ihnen wählen.

Dieser Ansatz ist nur aus der Geschichte des deutschen Krankenversicherungsrechts heraus erklärbar. ${ }^{149}$ Die bisher mit dem Kassenwettbewerb in Deutschland auf dem

148 Vgl. oben, II. 1. b).

149 Vgl. zu den Hintergründen nur Becker, Wettbewerb zwischen den öffentlichen Versicherungen in der gesetzlichen Krankenversicherung, ZSR 2000, S. 329 ff. Zur Diskussion in Österreich Hobel, Wettbewerb als Allheilmittel?, Soziale Sicherheit (Wien), 1996, S. 894 ff. 
Gebiet der gesetzlichen Krankenversicherung verbundenen Erfahrungen 150 sind durchaus zwiespältig. Die Verwaltungskosten sind eher gestiegen; der notwendige Risikostrukturausgleich ${ }^{151}$ kann nur mit hohem Aufwand durchgeführt werden. Es bleibt aber als nicht zu unterschätzender Pluspunkt eine geänderte Einstellung der Versicherungsträger gegenüber den Versicherten 152 und damit eine Verbesserung des Services. Dennoch setzt der Gesetzgeber auf eine Verstärkung des Wettbewerbs, ${ }^{153}$ und zwar nicht nur im Verhältnis zwischen gesetzlicher und privater Krankenversicherung, 154 sondern gerade auch durch Erweiterung der Möglichkeiten von Kassen, Leistungserbringer auszusuchen und mit diesen vertragliche Vereinbarungen zu treffen. ${ }^{155}$

2.1.2. Bei der zweiten Ausgestaltung wird auf ein Versicherungsmonopol verzichtet. Regelmäßig werden dann die Träger juristische Personen des Privatrechts sein, die aber zugleich eine öffentliche Aufgabe erfüllen, nämlich die Aufrechterhaltung einer ausreichenden Gesundheitsversorgung der Bevölkerung. Der Wettbewerb zwischen ihnen dient also der Sicherung einer sozialen Funktion. Das setzt eine über das bekannte Versicherungsrecht (mehr oder weniger stark) hinausgehende Regulierung der Privatversicherung voraus, ${ }^{156}$ nämlich die Einführung eines Aufnahme-(=Kontrahierungs-)zwangs sowie von staatlichen Regelungen über die Preise und die Mindestleistungen. Vermieden werden muß zumindest eine Risikoselektion. Zudem ist fraglich, ob die Leistungskontrolle den Versicherten überlassen werden kann. Auch die Regeln für die Prämiengestaltung liegen nicht von vornherein fest. Zwar sprechen für den Verzicht auf einen

150 Ausf. Überblick für die ersten Jahre bei Becker, Maßstäbe für den Wettbewerb unter den Krankenund Pflegekassen, in: Soziale Sicherheit und Wettbewerb, SDSRV 48 (2001), S. 7 ff.

151 Dazu und dessen Zulässigkeit Becker, Rechtliche Fragen im Zusammenhang mit dem Risikostrukturausgleich - unter Berücksichtigung der integrierten Versorgung, VSSR 2001, S. 277; BSG v. 24.1.2003, B 12 KR 19/01 R u.a. NZS 2005, S. 537 ff.; dazu Axer, Der Risikostrukturausgleich auf dem Prüfstand des Bundessozialgerichts, SGb 2003, S. 485 ff.; BVerfGE 113, 167, vgl. auch den Nichtannahmebeschluss v. 9.6.2004, 2 BvR 1248/03 u.a., NZS 2005, S. 139 ff.

$152 \mathrm{Ob}$ dies immer zugunsten der Versicherten ist, bliebe zu prüfen. Vgl. zu rechtliche Fragen der Patientenorientierung auch Pitschas, Deutsches und europäisches Gesundheitsrecht zwischen öffentlichrechtlicher Wettbewerbsordnung und Verbraucherschutz, in: Igl (Hrsg.), Das Gesundheitswesen in der Wettbewerbsordnung, 2000, 199, $207 \mathrm{ff}$.

153 Vgl. das GKV-Wettbewerbsstärkungsgesetz (WSG) v. 26.3.2007 (BGBl. I, S. 378).

154 Vgl. Kingreen, Die Annäherung von gesetzlicher und privater Krankenversicherung aus europarechtlicher Perspektive, ErsK 2007, S. 112 f.; ders., Soziale und private Krankenversicherung - Gemeinschaftsrechtliche Implikationen eines Annäherungsprozesses, ZESAR 2007, S. 139 ff.; Axer, Einbeziehung der PKV in die GKV, Standard- und Basistarif als Gegenstand der Sicherstellung in der vertragsärztlichen Versorgung, MedR 2008, S. 482 ff.

155 Vgl. die Beiträge in Pitschas (Hrsg.), Gesetzliche Krankenversicherung und Wettbewerb. Auf dem Weg zu einer wirklichen Gesundheitsreform, Frankfurt a.M:, Berlin u.a. 2008; ferner Becker, Das Wettbewerbsstärkungsgesetz - eine verfassungsrechtliche Bewertung, ZMGR 2007, S. $101 \mathrm{ff}$.

156 Ein gutes Beispiel dafür liefert die deutsche Pflegeversicherung, vgl. dazu krit. Isensee, Sozialversicherung über Privatversicherer - Rechtsprobleme der privaten Pflegeversicherung, in: FS für Gitter, 1995, S. 401 ff.; Axer, in: SDSRV 51 (2003) (Fußn. 114), S. 111, 119 ff. Akzeptiert wurde die Konstruktion trotz aller möglichen Einwände vom BVerfG (E 103, 197, 217 ff.). 
sozialen Ausgleich im Rahmen der Beitragsbemessung und die Einführung fester, einheitlicher Effizienzüberlegungen, weil Kosten durch einen aufwendigen Beitragseinzug und durch unerwünschte Selektion von guten Beitragszahlern vermieden werden können. Weil hinter den Systemen die Erfüllung einer öffentlichen Aufgabe steht, kommt auch eine einkommensbezogene Prämie in Betracht. Die statt dessen mögliche Quersubventionierung durch Steuermittel - m.a.W. die Verschiebung des sozialen Ausgleichs vom Sicherungssystem in den allgemeinen Staatshaushalt - führt nicht nur zu anderen verteilungspolitischen Effekten. Sie macht auch die Finanzierung von einer Bereitstellung von Haushaltsmitteln abhängig. Diese wird damit nicht mehr allein systemimmanent gesteuert, sondern führt auch umgekehrt aufgrund der rechtlichen Bindung des Haushaltsgesetzgebers zu einer bevorzugten Bedienung der Gesundheitskosten und damit zu einer möglicherweise unerwünschten Verengung der haushaltspolitischen Spielräume.

(1) In den Niederlanden sind die Krankenversicherungsträger privatrechtlich organisiert (vor allem als privatrechtliche Stiftungen oder als Versicherungsgesellschaften auf Gegenseitigkeit). Die Krankenversicherer stehen in einem regulierten Wettbewerb zueinander. Zwar müssen alle Versicherer die gesetzlich umschriebenen Leistungen der Basisversicherung anbieten (Art. 11 Krankenversicherungsgesetz), jedoch können sich die Verträge im übrigen in ihrer Ausgestaltung erheblich voneinander unterscheiden. Das betrifft die Höhe der eigentlichen Versicherungsprämie, während der einkommensbezogene Beitrag hoheitlich festgesetzt wird. Es betrifft ebenso die Leistungsarten (Sachleistung, Kostenerstattung oder eine Kombination), die Vereinbarung von Selbstbehalten und die Prämiennachlässe für Gruppenversicherungen, über die 57\% der Versicherten verfügen. Die Vereinbarung eines Selbstbehalts ist seit Beginn diesen Jahres verpflichtend geworden. Ein wichtiger Wettbewerbsfaktor sind auch die Zusatzversicherungen. Zwar dürfen die Angebote von Basis- und Zusatzversicherung nicht aneinander gekoppelt werden, dennoch werden häufig beide bei einem Versicherer abgeschlossen.

(2) Jeder, der in der Schweiz wohnt oder arbeitet, 157 muß sich nach dem Krankenversicherungsgesetz $(\mathrm{KVG})$ in der obligatorischen Krankenversicherung versichern. Die Versicherten haben aber die Wahlfreiheit, sich den Versicherer nach Art. 4 I KVG aussuchen zu können. Das wird ergänzt durch die Pflicht der Versicherer, gemäß Art. 4 II KVG jedermann in ihrem örtlichen Tätigkeitsbereich aufnehmen zu müssen. Die Versicherer dürfen nicht nach Risiken selektieren. Zu unterscheiden sind gemäß Art. 11 KVG die sog. sozialen Krankenversicherungen und private Versicherungsunternehmen, die aber bis heute nicht als Anbieter der obligatorischen Krankenversicherung auftreten. Die praktisch damit allein tätigen sozialen Krankenkassen dürfen keinen Erwerbszweck verfolgen. Sie können in Form einer juristischen Person des öffentlichen Rechts oder des Privatrechts errichtet werden, allerdings nur als Vereine, Stiftungen, Genossen-

157 Die zahlenmäßig geringfügigen Ausnahmen sind in den Art. 3 II-IV KVG und Art. 2-6 KVV genannt. 
schaften oder Aktiengesellschaften mit anderem als wirtschaftlichen Zweck. Anreize zur Wahl eines Versicherers können im Leistungsangebot und in der Höhe der Beiträge liegen. Bei ersterem sind im schweizerischen System der obligatorischen Krankenversicherung deutliche Einschränkungen vorgesehen, weil sich alle Leistungen am Leistungskatalog des KVG zu orientieren haben. Demnach ist hauptsächlicher Wettbewerbsfaktor die Gestaltung der Prämie. Diese ist eine Individualprämie, unabhängig von Einkommen oder Vermögen. Sie muß nach dem Prinzip der Einheitsprämie gestaltet, d.h. für alle Versicherten in einem geographisch eingrenzbaren Gebiet gleich hoch sein, und sie muß unabhängig von Geschlecht, Alter, Morbiditätsrisiko oder sonstigen in der Eigenschaft der Person liegenden Gründen sein. Zulässig sind aber Prämienermäßigungen. Sie gelten, wenn sich Versicherte entweder stärker an den jährlichen Behandlungskosten beteiligen oder ihre Wahlfreiheiten bezüglich der Leistungserbringer einschränken.

2.1.3. Die dritte Ausgestaltung ist durch eine reduzierte staatliche Sicherungsaufgabe gekennzeichnet. Bei ihr überläßt der Staat die Gewährung von Gesundheitsleistungen in erster Linie Privaten und damit dem Markt. Für dieses Modell stehen die USA. Dort wird die Gesundheitsversorgung immer noch weitgehend mit Beschäftigungsverhältnissen verbunden: Die Leistungen werden zwar nicht unmittelbar durch den Arbeitgeber gewährt, dieser vermittelt aber den Zugang zu Krankenversicherungen, die durch private Unternehmen getragen werden. ${ }^{158}$ Staatliche Programme sind nur für bestimmte, als besonders schutzbedürftig angesehene Personengruppen vorgesehen, nämlich zum einen für ältere Menschen (Medicare) und zum anderen für die Bezieher von Sozialhilfeleistungen (Medicaid). Allerdings ist die Ausgestaltung des Modells immer wieder in der Diskussion. ${ }^{159}$ Der Staat Massachusetts hat im Jahr 2006 ein Gesetz beschlossen (Ch. 58 of 2006, An act to provide access to affordable, quality, accountable health care), das eine Versicherungspflicht für alle Einwohner und eine Beihilfe für unterstützungsbedürftige Versicherte vorsieht und damit zugleich an dem bestehenden, die Rolle des Arbeitgebers in den Mittelpunkt stellenden Ansatz anknüpft. ${ }^{160}$ Und Anfang 2009 hat die neue Regierung einen Ausbau des Krankenversicherungsschutzes für Kinder (SCHIP) ${ }^{161}$ beschlossen. ${ }^{162}$

Bei dieser Ausgestaltung ist zumindest zu erwarten, daß die spezifische gesundheitsrechtliche (und damit sozialrechtliche) Regulierung hinter der allgemeinen Regulierung der Versicherungen, der Medizinprodukte und der Tätigkeit der Angehörigen von Heil-

158 Vgl. schon oben, II.2.3.

159 Hervorhebung verdient der gescheiterte Versuch der Clinton-Regierung, im Jahr 1993 einen health plan durchzusetzen, der alle Einwohner der USA erfassen sollte.

160 Vgl. zu einem ersten Überblick Raymond, Health Care Reform Law: One Year of Implementation, http://www.lawlib.state.ma.us/healthinsurance.html.

161 State Children's Health Insurance Program, vgl. http://www.cms.hhs.gov/home/schip.asp.

162 H.R.2, http://thomas.loc.gov/cgi-bin/query/D?c111:27:/temp/ c111dR3QmJ::. 
berufen zurücktritt und das Wettbewerbsrecht für das Verhältnis der Versicherungsträger, die untereinander in einem Wettbewerb stehen, eine wichtige Rolle spielt.

2.1.4. In die vorliegende Untersuchung werden die Länder einbezogen, die in Europa einem der vorliegenden Modelle folgen, d.h. einen Wettbewerb auf der Seite des Angebots von Krankenversicherungen auch dann ermöglichen, wenn diese Versicherungen als soziale eingestuft werden. Das sind, wie aus den genannten Beispielen folgt, neben Deutschland die Niederlande und die Schweiz. Abgerundet wird der Vergleich durch einen Länderbericht über die Krankenversicherung und die stationäre Versorgung in den USA. Denn damit kann auch das dritte der vorstehend vorgestellten Modelle in die Untersuchung einbezogen werden.

Dabei ist zu beachten, daß die Rechtsordnungen in drei von vier Vergleichsländern (Deutschland, Schweiz und USA) föderal angelegt sind und sich der Föderalismus auch im Gesundheitswesen niederschlagen kann. Zu nennen sind die Krankenhausplanung und die primär staatliche Investitionsfinanzierung in Deutschland, die auf Länderebene erfolgt und zu Wettbewerbsverzerrungen führen kann, obwohl oder gerade weil die inhaltlichen Vorgaben für die Gesundheitsversorgung auf Bundesrecht beruhen. Bis jetzt ist die volle Integration der Investitionsförderung in das DRG-System gescheitert, gegenwärtig wird aber einmal mehr die Umstellung der duralen Finanzierung diskutiert. In den Vereinigten Staaten existieren divergierende provider laws und variierende Medicaid-Programme für Geringverdienende, einige Staaten haben oder wollen darüber hinausgehend Pflichtversicherungen einführen. Und die Kantone spielen in der Schweiz gleich in verschiedener Hinsicht wichtige Rollen: Sie operieren als Akteure mit Versorgungsauftrag, mit Betreiberfunktion und als Kofinanciers zugleich.

\subsection{Konsequenzen für die Leistungserbringung}

2.2.1. Die Existenz mehrerer, untereinander in einem Wettbewerb stehender Versicherungsträger bedeutet keineswegs zwangsläufig, daß auch ein Wettbewerb zwischen den Leistungserbringern vorgesehen ist. $\mathrm{Zu}$ einem solchen Wettbewerb wird es regelmäßig kommen, wenn Versicherer mit bestimmten Leistungserbringern Verträge abschließen dürfen, um ihren Versicherten günstigere Behandlungskonditionen zu sichern.

Vorbild sind die $H M O$ s in den USA. Aber auch in der Schweiz sind entsprechende Absprachen vorgesehen. Dort schränken Versicherungsmodelle mit einer Ärzteliste (Preferred-Provider-Organization) die Wahl der Leistungserbringer dadurch ein, daß Versicherte, abgesehen von Notfallsituationen, nur Erbringer dieser Liste in Anspruch nehmen dürfen. Bei den speziellen HMO-Modellen willigt der Versicherte ein, sich nur von den Erbringern des HMO untersuchen oder behandeln und gegebenenfalls von diesen an Dritte überweisen zu lassen. Daneben existieren Hausarztmodelle, bei denen sich Versicherte verpflichten, immer erst einen bestimmten Allgemeinpraktiker aufzusuchen, der auch eine Budgetverantwortung übernimmt. Die Versicherte erhalten für alle diese 
Einschränkungen Prämienreduktionen. Die entsprechenden Anreize sind so wirksam, daß 2006 in der Schweiz nur noch 44 Prozent aller Versicherten über eine „normale“ Versicherung verfügten. ${ }^{163}$

Damit ist noch nicht gesagt, ob und in welchem Umfang Versicherer mit den Leistungserbringern eigenständig Tarife aushandeln dürfen. In der Schweiz müssen die Preise für die einzelnen Leistungen vertraglich vereinbart werden (mit Ausnahme der Vergütung von Analysen, von Arzneimitteln und sonstigen Sachmitteln, für die Behördentarife gelten), und zwar durch Einzel- oder Kollektivverträge (Art. 46 Abs. 1 KVG). In der Praxis dominiert die kollektivvertragliche Festlegung, wobei diese einem zweifachen Korrektiv unterliegen: Erstens sind sie durch eine staatliche Behörde zu genehmigen. Zweitens findet zusätzlich bei allen Tarifen, die Erhöhungen in der Vergütung nach sich ziehen, eine sog. Preisüberwachung (nach Art. 14 PüG) statt, mit der die Wirtschaftlichkeit der Tarife und das Fehlen eines Mißbrauchs kontrolliert wird.

In den Niederlanden wurden mit dem Gesetz zur Reform des Übereinkommensystems in der Gesundheitsversorgung (Wet herziening overeenkomstenstelsel zorg, Wet HOZ) die bis dahin bestehenden Modellübereinkommen als Grundlagen für die individuellen Leistungsverträge abgeschafft. Für die niedergelassenen Ärzte wurde der Kontrahierungszwang aufgehoben. Dieser kann vom Gesundheitsministerium für einzelne Leistungsbereiche wieder eingeführt werden. Hinsichtlich der Krankenhäuser wurde der Kontrahierungszwang 2005 zunächst für ca. 10\% der Leistungen aufgehoben, 2006 dann grundsätzlich ganz. Durch ministerielle Verordnung kann für bestimmte Einrichtungen aber auch hier wieder ein Kontrahierungszwang festgesetzt werden. Bislang wurde hiervon allerdings kein Gebrauch gemacht. Tatsächlich werden trotz der Neuregelungen in der Praxis kaum Einzelverträge abgeschlossen. Dies hat seine Ursache wohl zum einen in der geringen Dichte der Leistungserbringer und zum anderen in der Tradition der kollektiven Verträge durch die Berufsverbände. Auch wenn diese nach einer Entscheidung der Wettbewerbsbehörde keine Verträge über Tarifabsprachen mit bindender Wirkung für ihre Mitglieder abschließen dürfen, so haben diese Vereinbarungen doch die Wirkung von gentlemens agreements. ${ }^{164}$

2.2.2. Dürfen Versicherungsträger zwischen Leistungserbingern wählen, folgt daraus nicht zwangsläufig die Anwendbarkeit des von wettbewerbsrechtlichen Vorschriften. Zumindest für das europäische Gemeinschaftsrecht ist die derzeitige Anwendungspraxis durch eine gewisse Zurückhaltung geklärt. Entscheidend ist immer, ob die Handelnden, deren Maßnahmen auf Kartellwidrigkeit (Art. 81 EGV) oder Marktmißbrauch (Art. 82 EGV) hin überprüft werden soll, als Unternehmen einzustufen sind. In diesem Zusam-

163 Bundesamt für Sozialversicherungen (Hrsg.), Schweizerische Sozialversicherungsstatistik 2008, Bern 2008, S. 151.

164 van de Gronden, Mededingingsrecht en Gezondheidszorg, im Internet: http://igiturarchive.library.uu.nl/law/2005-0907-200601/article_print15.html. 
menhang hat der EuGH hat mit seiner Festbetragungsentscheidung 165 nicht nur die Unanwendbarkeit des Wettbewerbsrechts im Verhältnis zwischen Sozialversicherungsträger und Versichertem festgestellt, sondern aus der sozialen Funktion der Leistungserbringung auch auf dessen relativ weitgehende Unanwendbarkeit im Nachfrageverhältnis geschlossen. ${ }^{166}$ Damit schlägt die soziale Funktion aus dem Versicherungsverhältnis auf das Leistungserbringungsverhältnis durch, das als reines Beschaffungsverhältnis nicht unternehmerisch geprägt sein soll. ${ }^{167}$ Anwendbar ist dann möglicherweise das Vergaberecht, ${ }^{168}$ aber nur für die seltenen Fälle, in denen ein Dienstleistungsauftrag oder eine Rahmenvereinbarung und nicht nur eine Konzession abgeschlossen wird. 169 Dabei darf nicht übersehen werden, daß der Abschluß entsprechender Vereinbarungen zumindet temporär andere Wettbewerber ausschließt, also den Markt und damit Wahlmöglichkeiten der Versicherten verschließen kann. ${ }^{170}$

$\mathrm{Ob}$ die vom EuGH vertretene Folge zwangsläufig ist, erscheint ebenso fraglich wie deren genaue Reichweite. ${ }^{171}$ In jedem Fall ist das Ergebnis zu relativieren, und zwar unter Berücksichtigung der gesetzlichen Ausgestaltung des Leistungserbringungsrechts im konkreten Fall. Denn auch wenn Angebots- und Nachfrageseite bei der Gewährung von Sachleistungen wie medizinischen Behandlungen und Rehabilitationen nicht nur als benachbarte, sondern als sog. vertikale Märkte anzusehen sind, wenn also die Versicherungsträger unmittelbaren Einfluß auf die Leistungserbringung haben müssen und zu

165 EuGH v. 16.3.2004, Rs. C-264, 306, 354, 355/01 (AOK Bundesverband u.a.), Slg. 2004,. I-2493.

166 Vgl. zu der Entscheidung D. Neumann, EuGH EWiR Art. 81 EG 2/04, S. 435 f.; Koenig/Engelmann, Das Festbetrags-Urteil des EuGH: Endlich Klarheit über den gemeinschaftsrechtlichen Unternehmensbegriff im Bereich der Sozialversicherung?, EuZW 2004, S. 682 ff. Vgl. auch Mühlenbruch/Schmidt, Zur Einordnung der Tätigkeit von Krankenkassen hinsichtlich europäischem Wettbewerbsrecht und Dienstleistungsfreiheit, ZESAR 2004, S. 171 ff.; Schenke, Die Wettbewerbsposition der gesetzlichen Krankenversicherung im Spiegel des Europarechts, in: Schmehl/Wallrabenstein (Hrsg.), Steuerungsinstrumente im Recht des Gesundheitswesens, Bd. 1: Wettbewerb, 2005, S. 77, 88 ff.

167 So ausdrücklich EuGH v. 11.7.2006, Rs. C-205/03 (Fenin), Slg. 2006, I-6295.

168 In diesem Sinn jetzt EuGH v. 11.6.2009, Rs. C-300/07 (Oymanns), n.v.; vgl. zur vorhergehenden Diskussion Kingreen, Vergaberechtliche Anforderungen an die sozialrechtliche Leistungserbringung, SGb 2004, S. 659 ff.; V. Neumann/Nielandt/Philipp, Erbringung von Sozialleistungen nach Vergaberecht?, 2004, S. 56 ff.; Giesen, Wettbewerbsrecht, Vergaberecht und soziale Dienste, in: Linzbach/Lübking/Scholz/Schulte (Hrsg.), Die Zukunft der sozialen Dienste vor der Europäischen Herausforderung, 2005, S. 424, 440 ff. Vgl. auch die Entscheidung des BayObLG, BayObLGZ 2004, 122 = NZS 2005, 26; krit. dazu F. Wollenschläger, Die Bindung gesetzlicher Krankenkassen an das Vergaberecht, NZBau 2004, S. 655, 657 ff. m.w.N.; Byok/Jansen, Die Stellung gesetzlicher Krankenkassen als öffentliche Auftraggeber, NVwZ 2005, S. 53 ff.

169 Was etwa beim Abschluß von Versorgungsverträgen mit Krankenhäusern nach deutschem Recht nicht der Fall ist, vgl. Becker, in: ders./Kingreen (Hrsg.), SGB V, 2008 (Fußn. 25), § 108 Rdnr. 16.

170 Zur möglichen Verlagerung der Wahlmöglichkeiten innerhalb des Leistungsdreiecks oben, II. 1. b).

171 Vgl. aber auch Fuchs, Luxemburg locuta - causa finita - quaestio non soluta, NZS 2002, S. 337 ff.; zur Unmöglichkeit eines Marktes im sozialrechtlichen Dreiecksverhältnis V. Neumann, Kirchliche Karitas im Sozialstaat und in der europäischen Wettbeerbsordnung: Rechtsstauts, Konflikte und Perspektiven, RsDE 54 (2003), S. 1, 8 f. 
deren Sicherstellung gesetzliche Grundlagen erforderlich sind, ${ }^{172}$ schließt das eine Auswahl zwischen Leistungserbringern nicht aus. Das deutsche Krankenversicherungsrecht belegt dies eindrücklich. Im Rahmen der notwendigen gesetzlichen Vorgaben, mit denen die Erfüllung der sozialen Zwecke sichergestellt werden sollen, bleiben zunehmend Handlungsmöglichkeiten der Versicherungsträger. Zumindest in bestimmten Konstellationen „kaufen“ die Träger bei den Leistungserbringern die Leistungen „ein“ und haben dabei Auswahlentscheidungen zu treffen. ${ }^{173}$ Jedenfalls dort kann ein Wettbewerb nicht nur eingeschränkt Allokations- und Innovationsfunktionen erfüllen. Es muß vielmehr auch wettbewerbswidrigen Absprachen und einem Machtmißbrauch vorgebeugt werden. ${ }^{174}$ Das gilt selbst dann, wenn dem Wettbewerb im übrigen nicht die Steuerung der Bedarfsdeckung überlassen werden soll, wie auch durch Rahmenrecht zu verhindern ist, daß zu Lasten der Qualität ein reiner Preiswettbewerb stattfindet.

\section{Besonderheiten des Krankenhaussektors - zum Aufbau der Untersuchung}

\section{Krankenhäuser als institutioneller Ausgangspunkt}

Krankenhäuser sind Einrichtungen zur medizinischen Behandlung mit der Möglichkeit der Unterbringung von Patienten. Solche Einrichtungen existieren in allen Staaten, die überhaupt über ein Gesundheitssystem verfügen. Sie können in unterschiedlichen rechtlichen Formen betrieben werden. Als staatliche Einrichtungen werden sie oft rechtlich verselbständigt. Diese Verselbständigungstendenz gilt unabhängig von der Frage, auf welcher Ebene Krankenhäuser im Staatsaufbau verankert werden, also zugleich für regionale und kommunale Einrichtungen. In nicht wenigen Staaten können auch die in Privatrechtsform betriebenen Krankenhäuser an der Versorgung von Sozialversicherten teilnehmen. Im übrigen wird oft im privaten Sektor zwischen gemeinnützigen und gewerblichen Trägern unterschieden, was insofern von Bedeutung sein kann, als dann nicht alle Einrichtungen auf die Erzielung von Gewinn gerichtet sein müssen. Insgesamt zeigt sich damit eine Vielfalt an Organisations- und Rechtsformen. Allen Krankenhäu-

172 Dazu Drexl, Nationales Sozialrecht und europäisches Wettbewerbsrecht - Kommentar, in: Becker/Schön, (Hrsg.), Steuer- und Sozialstaat im europäischen Systemwettbewerb, 2006, S. 171, 183 f.

173 Zugegebenermaßen je nach Versorgungssektor und Dichte der gesetzlichen Vorgaben in unterschiedlichem Maße; vgl. dazu näher Becker, Gemeinschaftsrechtliche Einwirkungen auf das Vertragsarztrecht, in: Schnapp/Wigge, Handbuch des Vertragsarztrechts, 2. Aufl. 2006, § 22 Rdnr. 62 ff.

174 Das ist der Grund, warum § 69 SGB V mit dem pauschalen Ausschluß des (deutschen) Wettbewerbsrechts keine sinnvolle Lösung enthält. Vgl. auch Kingreen, Wettbewerbsrechtliche Aspekte des GKV-Modernisierungsgesetzes, MedR 2004, S. 188 ff. 
sern ist aber, unabhängig von der konkreten Bezeichnung und von den mit ihrem Betrieb im einzelnen verfolgten Zwecken, die eingangs genannte Funktion gemein: nämlich stationäre medizinische Behandlungen zu ermöglichen. Sie stellen deshalb einen geeigneten institutionellen Anknüpfungspunkt für eine rechtsvergleichende Untersuchung dar.

Weitere, auf die Art der Behandlung abstellende Präzisierungen sind für die Beschreibung des Vergleichsgegenstands ebenso wenig erforderlich wie überhaupt möglich. Weder kommt es darauf an, ob Krankenhäuser neben der Unterbringung eine Vielzahl medizinischer Behandlungsleistungen erbringen, möglicherweise gar bestimmte spezialisierte Behandlungen allein vornehmen, ${ }^{175}$ oder ob sie umgekehrt mit anderen Leistungserbringern kooperieren bzw. mit diesen in besonderen Behandlungszentren zusammengeschlossen sind. ${ }^{176}$ Noch kann entscheidend sein, ob jede medizinische Behandlung in ihnen stationär erfolgt. Schon die Abgrenzung von stationärer und ambulanter Behandlung ist fraglich. Sie kann zwar insoweit wichtig sein, als ein besonderes Planungsbedürfnis in erster Linie für Einrichtungen zur stationären Behandlung besteht. Die mit der Vorhaltung entsprechender entsprechender Einrichtungen verbundenen Kosten können dazu führen, deren Schaffung und Betrieb nicht den Marktmechanismen von Angebot und Nachfrage zu überlassen, sondern staatlich zu steuern. Das ist der Grund, warum der EuGH in seiner Rechtsprechung zur grenzüberschreitenden Inanspruchnahme von Behandlungsleistungen angenommen hat, Staaten dürften die Behandlung in Krankenhäusern trotz Anwendbarkeit der Dienstleistungsfreiheit von einem Genehmigungserfordernis abhängig machen. ${ }^{177}$ Jedoch ist damit keineswegs gesagt, $\mathrm{da} ß$ ein einheitliches Abgrenzungskriterium existiert, etwa eine Übernachtung das entscheidende Kriterium für die Definition der stationären Behandlung sein muß.178 Wichtiger für die Irrelevanz einer Unterscheidung von stationärer und ambulanter Versorgung zur Festlegung des Ausgangspunkts der Untersuchung ist der Umstand, daß nicht alle Gesundheitssysteme überhaupt eine klare Trennung zwischen ambulanter und stationärer Behandlung vorsehen. Selbst in Deutschland sind die Grenzen mittlerweile nicht nur durch die Zulassung ambulanter Behandlungen in Krankenhäusern, ${ }^{179}$ sondern

175 Wenn etwa ein ausgebautes Facharztwesen nicht existiert.

176 Wie etwa in Form der Medizinischen Versorguingszentren in Deutschland.

177 EuGH v. 12.7.2001, Rs. C-157/99 (Smits u. Peerbooms), Slg. 2001, S. I-5473. Dazu nur Bieback, Etablierung eines Gemeinsamen Marktes für Krankenbehandlung durch den EuGH, NZS 2001, S. 561 ff.; Kingreen, Zur Inanspruchnahme von Gesundheitsleistungen im europäischen Binnenmarkt, NJW 2001, S. $3382 \mathrm{ff}$.

178 Vgl. dazu etwa Becker/Walser, Stationäre und ambulante Krankenhausleistungen im grenzüberschreitenden Dienstleistungsverkehr - von Entgrenzungen und neuen Grenzen in der EU, NZS 2005, S. $449 \mathrm{ff}$.

179 Auf der Grundlage der $\S \S 116$ ff. SGB V, wobei zwischen persönlichen und institutionellen Ermächtigungen zu unterscheiden ist. 
ebenso durch integrierte Versorgungsformen verwischt, wenn auch nicht aufgehoben. ${ }^{180}$

\section{Zu den Rechtsverhältnissen bei der Versorgung im Krankenhaus}

Die Analyse normativ fundierter Steuerungskonzepte durch wettbewerbsorientierte Anreizfunktionen setzt vor allem bei den Akteuren und den jeweiligen Rechtsverhältnissen zwischen ihnen an. Ausgangspunkt ist die bereits beschriebene Dreiecksbeziehung, 181 die für das Leistungserbringungsverhältnis in der Krankenhausversorgung prägend ist, und zwar unabhängig davon, ob der Träger der Krankenversicherung ein privates Versicherungsunternehmen oder eine Verwaltungsbehörde ist.

Dementsprechend sind verschiedene Wahlmöglichkeiten bzw. Wettbewerbssituationen voneinander zu unterscheiden. Um mit dem Versicherten bzw. Patienten zu beginnen: Er kann in vielen Fällen das Krankenhaus, in dem er eine Behandlung durchführen lassen möchte, auswählen. Dabei dürften Gesichtspunkte wie Qualität und räumliche Nähe eine besondere Rolle spielen, der Preis hingegen nur, soweit er neben der Versicherung überhaupt Anreizwirkung entfalten kann. Letzteres wird selten der Fall sein. Insbesondere Eigenanteile oder Zuzahlungen dürften in der Regel zu keinen nach Leistungserbringern abgestuften finanziellen Belastungen führen.

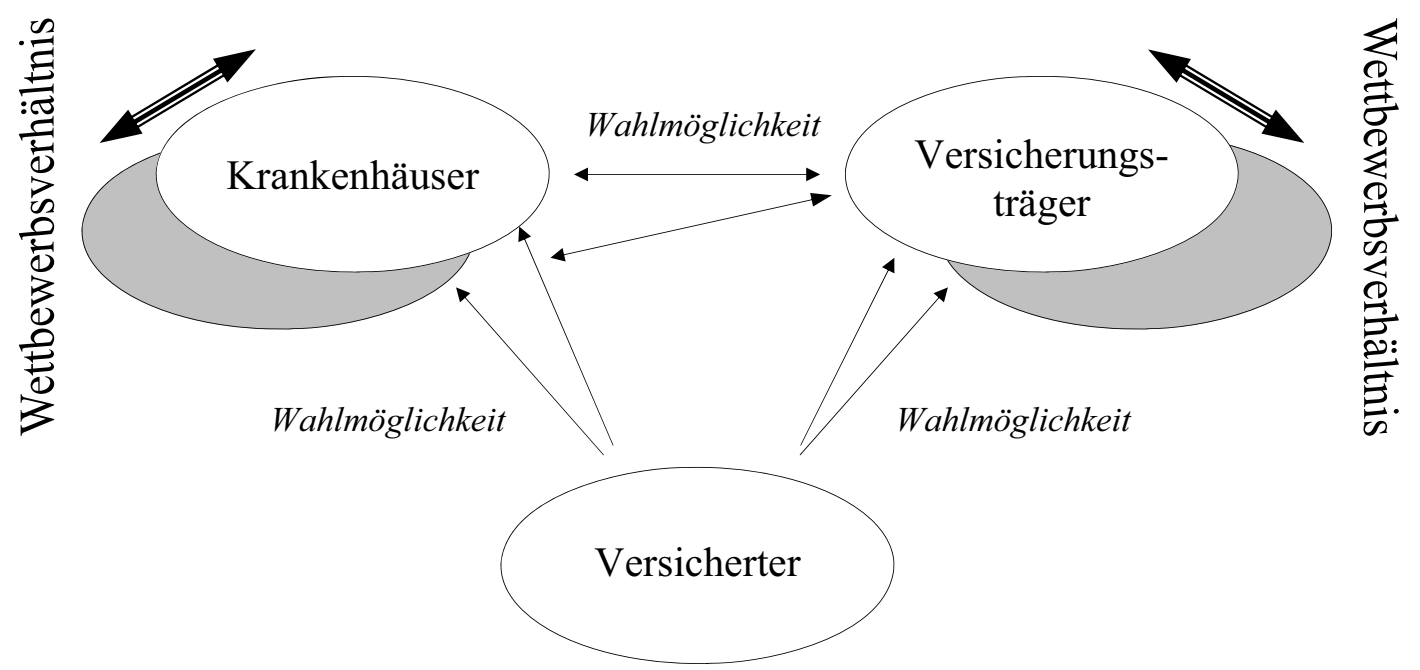

In gewisser Weise eingebettet ist die Entscheidung für ein bestimmtes Krankenhaus in die zeitlich vorangehende Wahl der Versicherung und des Versicherungsträgers. Mit der letztgenannten Wahl kann, je nach rechtlichen Vorgaben, der Umfang der Versiche-

180 Vgl. zu früheren Forderungen einer engeren Verzahnung nur die Gutachten des Sachverständigenrats für die Konzertierte Aktion im Gesundheitswesen, Sachstandbericht 1994, Rdnr. 352 ff.; Gesundheitsversorgung und Krankenversicherung 2000, Rdnr. $230 \mathrm{ff}$.

181 Vgl. oben. II. 1. c). 
rung, in allen Vergleichsländern grundsätzlich aber auch die Einrichtung, welche die Versicherung durchführt, ${ }^{182}$ ausgesucht werden.

Entsprechende Wahlmöglichkeiten führen zu einem Preis-, aber auch einem Qualitätswettbewerb zwischen Versicherern, wobei aus Sicht des Versicherten für die Beurteilung der Qualität wiederum die Leistungserbringung von wesentlicher Bedeutung sein wird. Die Wahl der Versicherung und die Wahl des Krankenhauses können deshalb miteinander verkoppelt sein, nämlich dann, wenn der Versicherer mit bestimmten Leistungserbringern kooperiert. Allerdings ist die Güte einer medizinischen Behandlung für Patienten ohnehin nur schwer einschätzbar. ${ }^{183}$ Dazu kommt, daß auch fehlende Erfahrungen mit eigenverantwortlichem Handeln oder fehlende Entschlußfähigkeit ${ }^{184}$ rationales Handeln erschweren und gerade diejenigen, die Sozialleistungen in Anspruch nehmen (müssen), aus verschiedenen Gründen in ihren Entscheidungsmöglichkeiten beschränkt sind oder zu Entscheidungen neigen, die die Zwecksetzung eines Leistungssystems gefährden. ${ }^{185}$ Diesen Hindernissen für marktkonformes Verhalten sollen versicherungs- und sozialrechtliche Vorgaben begegnen, die zugleich die Spielräume für den Wettbewerb zwischen den Versicherern beschränken.

Ebenfalls beschränkt werden muß der Wettbewerb zwischen den Krankenhäusern, und zwar unabhängig davon, ob er durch Auswahlentscheidungen der Versicherten bzw. Patienten oder durch die Möglichkeit von Versicherern, mit Leistungserbringern selektive Verträge zu schließen, induziert wird. Denn erstens existieren in den meisten Staaten rechtliche Vorschriften, die im Sinne des Gesundheitsschutzes die Tätigkeit von Krankenhäusern regulieren, eventuell die Aufnahme dieser Tätigkeit auch von einer Zulassung oder dem Abschluß von Versorgungsverträgen abhängig macht. Dabei ist eine Tendenz erkennbar, einfache Mindestanforderungen durch eine umfassende Qualitätssicherung zu ersetzen. Zweitens wird ein Staat grundsätzlich dafür sorgen wollen, daß es überhaupt in ausreichendem Umfang Versorgungsmöglichkeiten gibt, also genügend Krankenhäuser für Behandlungen zur Verfügung stehen. Was genügend ist, bedarf der politischen Entscheidung. Aber die Sicherung eines Mindestbestandes bleibt ungeachtet dessen in den meisten Staaten ein allgemeines politisches und rechtliches Ziel. In diesem Sinn besteht eine staatliche Infrastrukturverantwortung. Dem Markt kann deshalb die Krankenhausversorgung nicht völlig überlassen werden. Wettbewerb als Entdeckungsverfahren ist ein Verfahren zur Entdeckung von Handlungsoptionen, die ohne sein Bestehen entweder unbekannt bleiben oder doch zumindest nicht genutzt werden

\footnotetext{
182 Dazu bereits oben, IV. 2. a).
}

183 Vgl. zu Informationsdefiziten Breyer/Zweifel/Kifmann, Gesundheitsökonomik, 5. Aufl. 2004, S. 179 ff.; zusammenfassend Spiecker gen. Döhmann, Zur Wettbewerbsfähigkeit der Gesundheitsgüter, in: Schmehl/Wallrabenstein (Hrsg.), Steuerungsinstrumente im Recht des Gesundheitswesens, Bd. 1: Wettbewerb, 2005, S. 1, $13 \mathrm{ff}$.

184 Näher Nullmeier, Vermarktlichung des Sozialstaats, WSI Mitt. 9/2004, S. 495, 497 f.

185 Das gilt für steuerfinanzierte Leistungen ebenso wie für Zwangsversicherungen, wenn dort eine Spreizung der Prämien bzw. Beiträge je nach Inanspruchnahme von Gütern nicht vorgesehen ist. 
würden. ${ }^{186}$ Es wäre nicht notwendig, wenn seine Ergebnisse vorhersagbar wären. ${ }^{187}$ Mit einer solchen Unsicherheit verträgt sich die Infrastrukturverantwortung nicht. Es sind deshalb zumindest Sicherungen erforderlich, die eine Ergebniskontrolle ermöglichen. Dafür eingesetzte Instrumente reichen von einer Planung nach Bedarfsgrößen über eine Steuerung des Zugangs von Patienten bis zu einer Insolvenzsicherung.

\section{Zur Einbettung in die Gesamtrechtsordnung und den faktischen Hintergründen}

Die folgenden Länderberichte nehmen in ihrem zweiten Teil die vorstehend beschriebene Unterscheidung von Rechts- und Wettbewerbsverhältnissen auf und stellen diese im einzelnen dar. Sie befassen sich eingehend mit den Grenzen und Möglichkeiten der jeweiligen Wahlentscheidungen und beschreiben die zu deren Regelung eingesetzten rechtlichen Instrumente.

Welche Instrumente zur Verfügung stehen und auch, wie diese zu bewerten sind, hängt nicht zuletzt von den normativen und faktischen Rahmenbedingungen ab. Deshalb wird in einem ersten Teil der Länderberichte auf die verfassungsrechtlichen Vorgaben und die grundsätzliche Anlage des Gesundheitswesens eingegangen, wobei auch die wichtigsten Kennzahlen zur Krankenhausversorgung genannt werden.

186 Vgl. v. Hayek, Der Wettbewerb als Entdeckungsverfahren, 1968, S. 3.

187 Vgl. v. Hayek, Recht, Gesetz und Freiheit, 2003, S. 374 f. 
